\title{
Chimeric Cellobiose Dehydrogenases Reveal the Function of Cytochrome Domain Mobility for the Electron Transfer to Lytic Polysaccharide Monooxygenase
}

Alfons K. G. Felice, Christian Schuster, Alan Kadek, Frantisek Filandr, Christophe V. F. P. Laurent, Stefan Scheiblbrandner, Lorenz Schwaiger, Franziska Schachinger, Daniel Kracher, Christoph Sygmund, Petr Man, Petr Halada, Chris Oostenbrink, and Roland Ludwig*

Cite This: ACS Catal. 2021, 11, 517-532

Read Online

ABSTRACT: The natural function of cellobiose dehydrogenase $(\mathrm{CDH})$ to donate electrons from its catalytic flavodehydrogenase (DH) domain via its cytochrome (CYT) domain to lytic polysaccharide monooxygenase (LPMO) is an example of a highly efficient extracellular electron transfer chain. To investigate the function of the CYT domain movement in the two occurring electron transfer steps, two $\mathrm{CDHs}$ from the ascomycete Neurospora crassa (NcCDHIIA and NcCDHIIB) and five chimeric $\mathrm{CDH}$ enzymes created by domain swapping were studied in combination with the fungus' own LPMOs (NcLPMO9C and NcLPMO9F). Kinetic and electrochemical methods and hydrogen/deuterium exchange mass spectrometry were used to study the domain movement, interaction, and electron transfer kinetics. Molecular

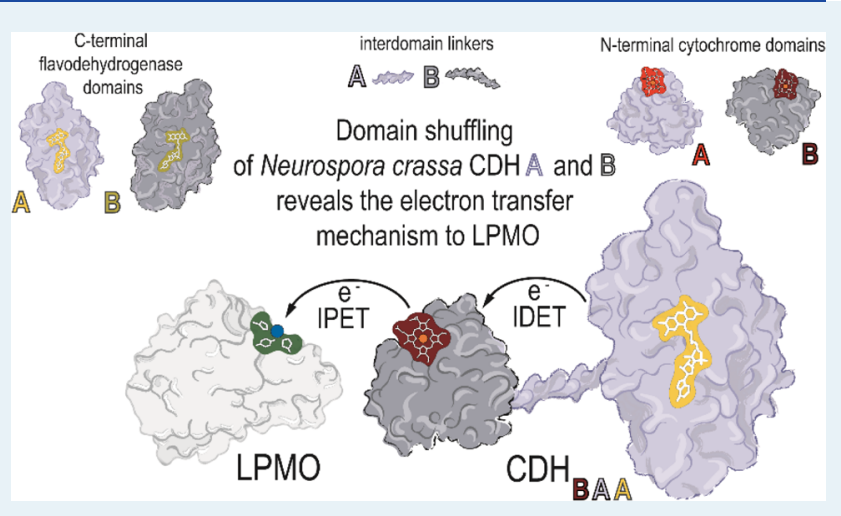
docking provided insights into the protein-protein interface, the orientation of domains, and binding energies. We find that the first, interdomain electron transfer step from the catalytic site in the DH domain to the CYT domain depends on steric and electrostatic interface complementarity and the length of the protein linker between both domains but not on the redox potential difference between the FAD and heme $b$ cofactors. After CYT reduction, a conformational change of $\mathrm{CDH}$ from its closed state to an open state allows the second, interprotein electron transfer (IPET) step from CYT to LPMO to occur by direct interaction of the $b$-type heme and the type- 2 copper center. Chimeric CDH enzymes favor the open state and achieve higher IPET rates by exposing the heme $b$ cofactor to LPMO. The IPET, which is influenced by interface complementarity and the heme $b$ redox potential, is very efficient with bimolecular rates between $2.9 \times 10^{5}$ and $1.1 \times 10^{6} \mathrm{M}^{-1} \mathrm{~s}^{-1}$.

KEYWORDS: cellobiose dehydrogenase, chimeric enzyme, domain swapping, electron transfer, lytic polysaccharide monooxygenase

\section{INTRODUCTION}

The catalytic activity of lytic polysaccharide monooxygenase (LPMO) and its interaction with cellobiose dehydrogenase $(\mathrm{CDH})$ have been reported to increase the rate of cellulose hydrolysis from the recalcitrant biomass and to increase the overall efficiency of enzymatic cocktails. ${ }^{1-5}$ In contrast to electron-donating, low-molecular weight reductants of LPMO such as gallate or ascorbate, $\mathrm{CDH}$ is specific for LPMO and shows a fast electron transfer at physiological concentrations. ${ }^{6,7}$ $\mathrm{CDH}$ is an extracellular flavocytochrome and contains FAD and a $b$-type heme in the flavodehydrogenase $(\mathrm{DH})$ and cytochrome (CYT) domains, respectively, which are connected via a flexible linker. The electron transfer between the domains is $\mathrm{pH}$ dependent and has been studied by Igarashi and coworkers in detail. ${ }^{8}$ Recently, the structure of the full-length protein has been elucidated and two conformations (closedand open state) of the CYT domain were observed, which are supposed to play a role in interdomain electron transfer (IDET) and interprotein electron transfer (IPET). ${ }^{9}$

LPMO activation by $\mathrm{CDH}$ comprises three steps: (i) catalytic cellobiose oxidation in the $\mathrm{DH}$ active site leads to the formation of the reduced $\mathrm{FAD}$ cofactor, (ii) interaction of CYT with $\mathrm{DH}$ in the closed state results in the subsequent one-electron IDET, and (iii) interaction of CYT in the open state with LPMO results in the one-electron IPET. In the closed state of $\mathrm{CDH}$, the $\mathrm{FAD}$ and heme $b$ cofactors are in close proximity $(\sim 0.9 \mathrm{~nm})$, which should favor IDET, whereas

Received: December 3, 2020

Revised: December 11, 2020

Published: December 24, 2020 
A

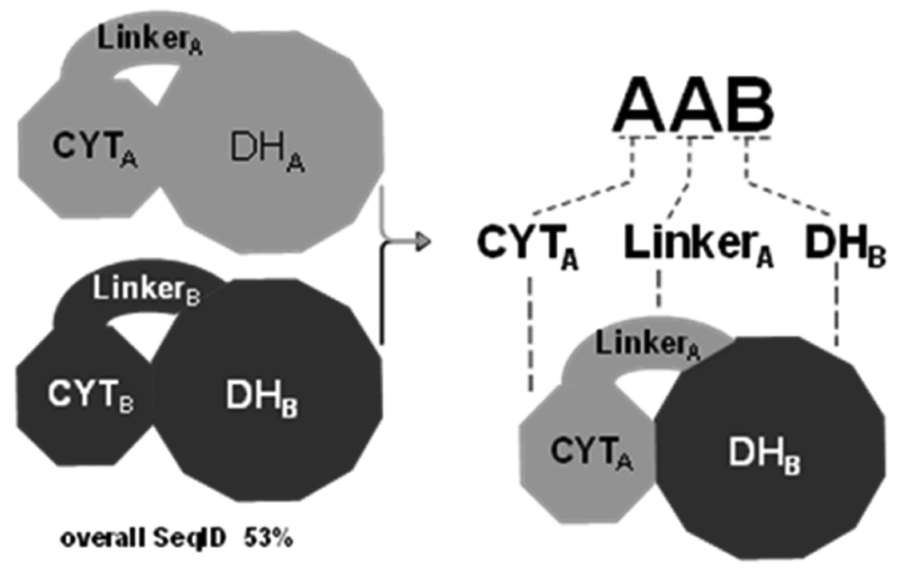

B
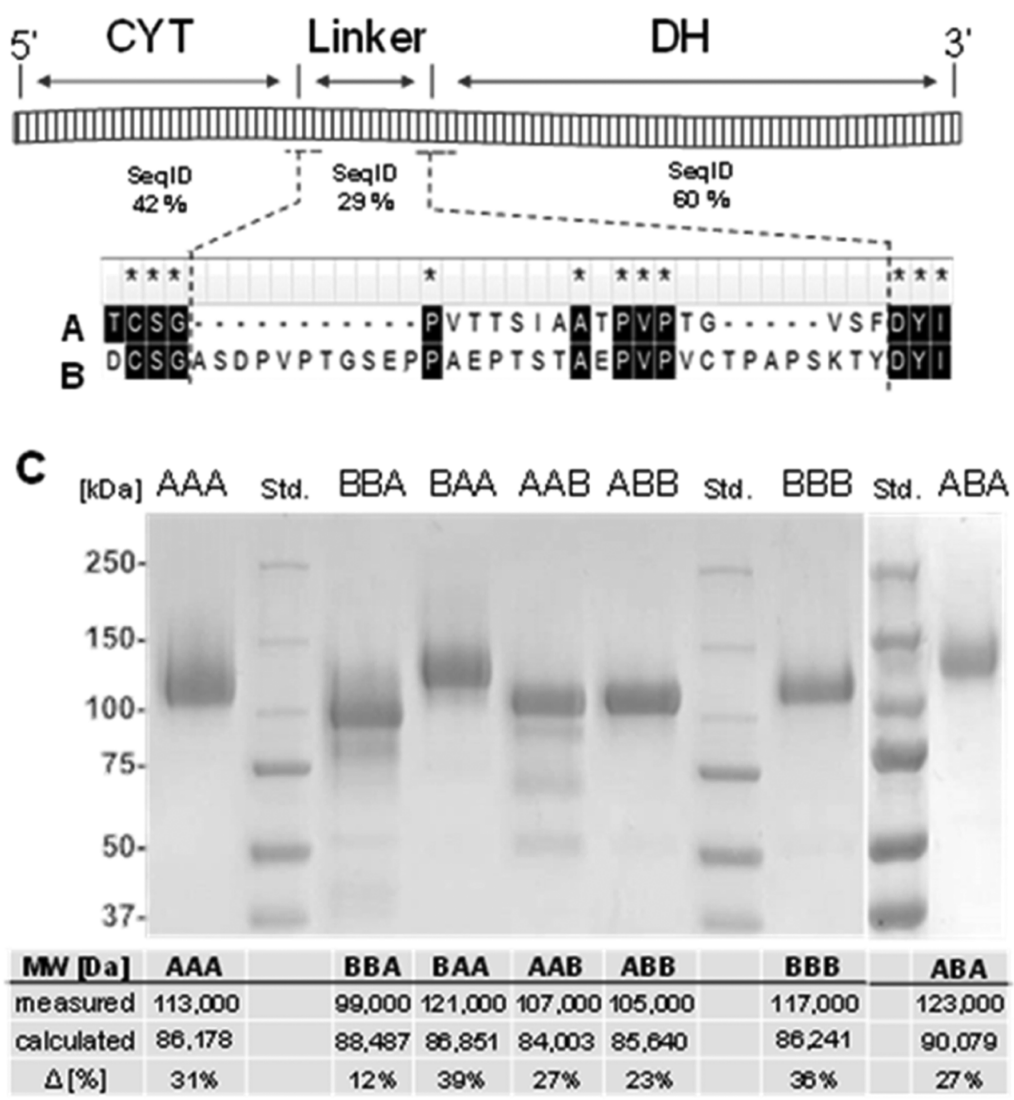

Figure 1. Properties of chimeric enzymes. (A) Domain architecture. The two N. crassa wild-type CDHs (CDHIIA denoted CDH AAA $_{\text {and CDHIIB }}$ denoted $\mathrm{CDH}_{\mathrm{BBB}}$ ) consist of an $\mathrm{N}$-terminal $\mathrm{CYT}$ domain, $\mathrm{C}$-terminal $\mathrm{DH}$ domain, and a protein linker connecting the two domains. Four chimeric $\mathrm{CDHs}\left(\mathrm{CDH}_{\mathrm{BBA}}, \mathrm{CDH}_{\mathrm{BAA}}, \mathrm{CDH}_{\mathrm{AAB}}\right.$, and $\left.\mathrm{CDH}_{\mathrm{ABB}}\right)$ were created by domain swapping. (B) Linker sequence and position in $\mathrm{CDH}$. The alignment shows sequence identities and the $\mathrm{N}$ - and $\mathrm{C}$-terminal ends of the linkers. (C) Purified wild-type and chimeric CDHs. The measured and calculated molecular weights differ due to glycosylation.

IPET depends on the interaction of the heme $b$ with LPMO, 9 which should be favored in the open state. The structure of the linker in the open- or closed states could not be fully determined in crystal structures, which indicates its high flexibility.

The two CDHs encoded in the genome of Neurospora crassa provide a good basis to study the influence of the CYT mobility on electron transfer because of several reasons. First, the structure of NcCDHIIA has been elucidated (PDB ID: 4QI7), and second, a comparison of the steady-state kinetic constants of the two CDHs in a previous study found a 3.5-fold faster IDET rate for NcCDHIIA at $\mathrm{pH} 6.0$ compared to
$\mathrm{NcCDHIIB}$ despite the $\sim 50 \mathrm{mV}$ higher redox potential of the heme $b$ cofactor. $^{7}$ The independence of the IDET rate from the electrochemical driving force suggests a different function of both enzymes' CYT domains, possibly an adaptation to the copper center redox potentials of different LPMOs. ${ }^{7}$ Structural features of the domains and surface charge distribution have been shown to influence the $\mathrm{CDH}$ domain interaction kinetics. ${ }^{10,11}$ SAXS and SANS studies showed that the oxidized form of $\mathrm{CDH}$ populates a variety of conformational states between the closed- and fully open state and that $\mathrm{pH}$, presence of divalent cations, and the presence of LPMO modulate the occupation of the closed- and open states. ${ }^{12,13}$ Fast scanning 

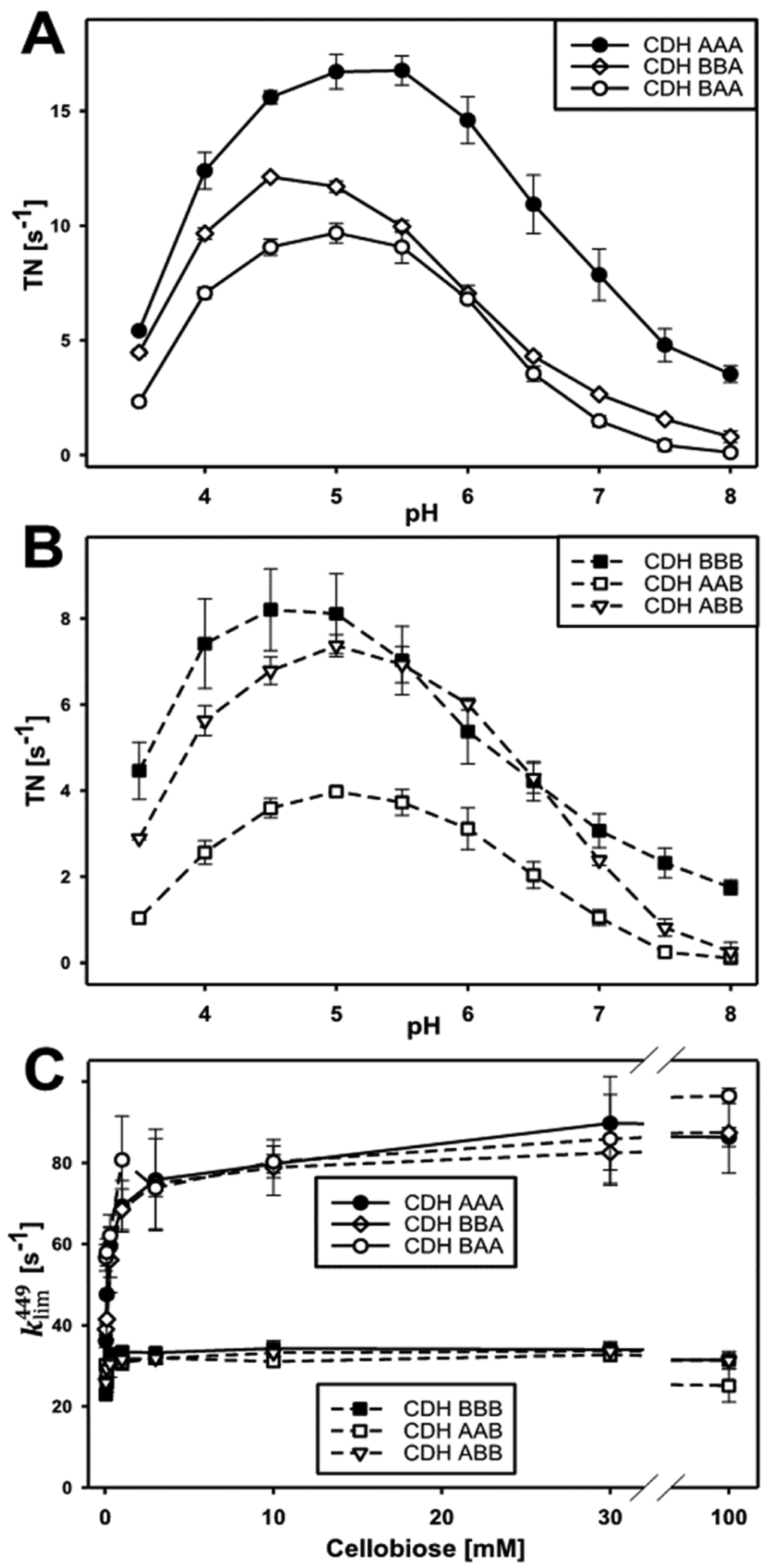

Figure 2. Effects of domain swapping on catalytic rates in the $\mathrm{DH}$ domain. (A) $\mathrm{pH}$ optima of cellobiose conversion in $\mathrm{CDH}_{\mathrm{H}}$ with a $\mathrm{DH}_{\mathrm{A}}$ when using the two-electron acceptor 2,6-dichloroindophenol. (B) $\mathrm{pH}$ optima of $\mathrm{CDH}$ s with a $\mathrm{DH}_{\mathrm{B}}$ using the same substrate and cosubstrate as in (A). (C) FAD reduction rate in all CDHs measured at $449 \mathrm{~nm}\left(k_{\mathrm{obs}}{ }^{449}\right)$ for increasing cellobiose concentrations.

AFM studies showed a preference of the open state in the reduced form of $\mathrm{CDH} .{ }^{14}$ These observations raise the question of how CYT interacts with either DH or LPMO and which structural and kinetic determinants govern this interaction. 
Table 1. Catalytic Constants, Transient Rates, and FAD Redox Potentials of CDHs ${ }^{a}$

\begin{tabular}{lr} 
enzyme & \multicolumn{1}{c}{$k_{\text {cat }}\left[\mathrm{s}^{-1}\right]$} \\
$\mathrm{CDH}_{\mathrm{AAA}}$ & $17.8 \pm 0.4$ \\
$\mathrm{CDH}_{\mathrm{BAA}}$ & $9.0 \pm 0.3$ \\
$\mathrm{CDH}_{\mathrm{BBA}}$ & $14.2 \pm 0.4$ \\
$\mathrm{CDH}_{\mathrm{ABA}}$ & $9.1 \pm 0.2$ \\
$\mathrm{CDH}_{\mathrm{BBB}}$ & $4.6 \pm 0.1$ \\
$\mathrm{CDH}_{\mathrm{ABB}}$ & $5.0 \pm 0.1$ \\
$\mathrm{CDH}_{\mathrm{AAB}}$ & $4.5 \pm 0.2$
\end{tabular}

$K_{\mathrm{M}}[\mathrm{mM}]$
$0.105 \pm 0.003$
$0.057 \pm 0.006$
$0.075 \pm 0.005$
n.d.
$0.027 \pm 0.002$
$0.026 \pm 0.003$
$0.046 \pm 0.003$

$k_{\text {cat }} / K_{\mathrm{M}}\left[\mathrm{M}^{-1} \mathrm{~s}^{-1}\right]$

$1.7 \times 10^{5}$
$1.6 \times 10^{5}$
$1.9 \times 10^{5}$
n.d.
$1.7 \times 10^{5}$
$1.9 \times 10^{5}$
$1.0 \times 10^{5}$

$k_{\lim }{ }^{449}\left[\mathrm{~s}^{-1}\right]$
$81.8 \pm 2.2$
$82.2 \pm 2.6$
$79.8 \pm 2.4$
$89.6 \pm 2.3$
$33.5 \pm 0.4$
$32.3 \pm 0.4$
$30.4 \pm 0.6$

$E$ vs $\mathrm{SHE}[\mathrm{mV}]$

$33 \pm 5$

$24 \pm 5$

$31 \pm 1$

n.d.

$43 \pm 15$

$33 \pm 23$

n.d.

${ }^{a}$ The steady-state catalytic constants of the DH domains in wild-type and chimeric CDHs were determined for cellobiose as substrate and 2,6dichloroindophenol as saturating co-substrate. Transient FAD reduction rates $\left(k_{\mathrm{obs}}{ }^{449}\right)$ measured in a stopped-flow spectrophotometer at different cellobiose concentrations were used to extrapolate the maximal reduction rate of FAD for an infinite cellobiose concentration $\left(k_{\text {lim }}{ }^{449}\right)$. The midpoint redox potentials $\left(E^{1 / 2}\right)$ of the FAD cofactor in regard to the SHE was determined in a spectroelectrochemical cell is given in the last column. All measurements were performed at $\mathrm{pH}$ 6.0. n.d.: not determined because of too small amount of chimeric $\mathrm{CDH}$.

Based on sequence alignment and the elucidated crystal structures, we created chimeric $\mathrm{CDH}$ enzymes by exchanging linker, CYT, and DH domains of the two NcCDHs to study the role of the CYT-DH interface, the effect of different cofactor redox potentials, and the influence of the linker length on the protein-protein interaction and IDET. CYT-LPMO interaction was also studied by hydrogen/deuterium exchange mass spectrometry (HDX-MS) measurements and transientstate kinetics to determine the interaction site of $\mathrm{CDH}-$ LPMO. We also evaluated the structural and kinetic determinants of the domain interaction to test recent results obtained by Courtade et al., who showed the binding of $\mathrm{CDH}$ and CYT to the LPMO active site by means of ${ }^{15} \mathrm{~N}-\mathrm{HSQC}$ and ${ }^{13} \mathrm{C}$-aromatic-HSQC, ${ }^{15}$ and by Laurent et al. who modeled the interaction between both enzymes. ${ }^{16}$

To study the effect of (i) the surface complementarity at the protein-protein interface, (ii) differences in the redox potentials of the cofactors, and (iii) the linker length on the domain interaction and the electron transfer rate, a domain swapping strategy was applied to create chimeric enzymes of the two N. crassa CDHs by exchanging CYT and linkers with different structural and physical properties. The chimeric $\mathrm{CDHs}$ were studied by steady-state and presteady-state kinetics, electrochemical methods, and molecular modeling in combination with two N. crassa LPMOs.

\section{RESULTS}

Construction and Properties of Chimeric CDH Variants. A domain swapping strategy was applied to exchange linkers and CYT domains of the two $N$. crassa $\mathrm{CDHs}$ (Figure 1A). The sequence alignment of NcCDHIIA (UniProt: Q7RXM0) with NcCDHIIB (UniProt: Q7S0Y1) gives a sequence identity of $53 \%$ and was used together with the crystal structure of NcCDHIIA (PBD ID: 4QI7) and a homology model of $\mathrm{NcCDHIIB}$ to define the individual $\mathrm{CDH}$ domains. The end of the $\mathrm{N}$-terminal CYT domain is defined by a cysteine residue forming a disulfide bond $\left(\mathrm{CYT}_{\mathrm{A}}\right.$ : $\mathrm{Q} 1-\mathrm{C} 211$, $\mathrm{CYT}_{\mathrm{B}}$ : Q1-C216, for brevity, we denote the domains and the linker of NcCDHIIA by $\mathrm{A}$ and NcCDHIIB by B). This disulfide bond in CYT is found in several CDHs and possibly evolved to stabilize the $\mathrm{C}$-terminus against mechanical stress exerted by the linker. After this cysteine, the linker sequence starts (linker ${ }_{A}:$ S212-S229, linker $_{B}:$ S217-T250). The DH domain starts with the first amino acid firmly connected with $\mathrm{DH}$ and ends with the C-terminus $\left(\mathrm{DH}_{\mathrm{A}}\right.$ : F230-V772, $\mathrm{DH}_{\mathrm{B}}$ : Y251-R805). The C-terminus of NcCDHIIA features an additional family 1 carbohydrate-binding module (CBM1,
P773-V806), which is not present in NcCDHIIB. Because in this study the binding of CDHs to cellulose is not interfering with the experiments, the CBM1 was not removed. It is present in all chimeric $\mathrm{CDH}$ with a $\mathrm{DH}_{\mathrm{A}}$ domain. The sequence identities of individual linkers, CYT and DH domains deviate considerably from the global sequence identity (Figure 1B). The catalytically active DH domains are most conserved, the linkers least. The linkers of both enzymes are rich in serine, threonine, and proline but differ substantially in length. Linker $_{\mathrm{A}}$ consists of 17 amino acids, while $\operatorname{linker}_{\mathrm{B}}$ is twice as long and consists of 33 amino acids. The evolutionary divergence of the CYT domains and linkers points toward different mechanistic properties, physiological functions, and interacting LPMOs.

Production and Purification of Enzymes. Wild-type $N$. crassa CDHs (NcCDHIIA denoted $\mathrm{CDH}_{\mathrm{AAA}}$ and $\mathrm{NcCDHIIB}$ denoted $\left.\mathrm{CDH}_{\mathrm{BBB}}\right)$ and five chimeric $\mathrm{CDHs}\left(\mathrm{CDH}_{\mathrm{AAB}}\right.$, $\mathrm{CDH}_{\mathrm{ABB}}, \mathrm{CDH}_{\mathrm{BBA}}, \mathrm{CDH}_{\mathrm{BAA}}$, and $\left.\mathrm{CDH}_{\mathrm{ABA}}\right)$ were recombinantly produced in Pichia pastoris and chromatographically purified (Figure S1 and Table S1). LPMO9C and LPMO9F from $N$. crassa were also produced in $P$. pastoris and chromatographically purified. The molecular weight of the individual domains and linkers can be calculated from the amino acid sequence and summed up to obtain molecular weights for full-length $\mathrm{CDHs}$ (Figure 1C). Similar molecular weights for the two wild-type enzymes $\mathrm{CDH}_{\mathrm{AAA}}$ and $\mathrm{CDH}_{\mathrm{BBB}}$ are predicted, and also between the smallest and largest chimeric enzymes $\left(\mathrm{CDH}_{\mathrm{AAB}}\right.$ and $\mathrm{CDH}_{\mathrm{BBA}}$, respectively) the mass difference is only $4484 \mathrm{Da}$. The molecular weights of the six purified $\mathrm{CDH}$ determined by sodium dodecyl sulphatepolyacrylamide gel electrophoresis (SDS-PAGE) differ from the calculated values. The observed molecular weights are 12$39 \%$ larger and a result of posttranslational $N$-glycosylation ${ }^{17}$ and $O$-glycosylation. ${ }^{18}$ Considerable differences in the glycosylation, even between structurally quite similarly built chimeric $\mathrm{CDH}_{\mathrm{BBA}}$ and $\mathrm{CDH}_{\mathrm{BAA}}$, point toward batch-to-batch variations between fermentations or differences in the posttranslational processing of the chimeric CDHs. This heterogeneity of glycoforms is also known from homologously secreted CDHs and cannot be avoided so far. A deglycosylation of $\mathrm{CDH}$ results in low stability and solubility. The effects of differences in the $\mathrm{O}$-glycosylation of the linker are unknown but might influence its flexibility. Bivariate correlation analysis of the mass percentage of each CDH's glycosylation shows no correlation with the domain composition in wild-type or chimeric $\mathrm{CDH}$ and also no correlation with the observed catalytic- or electron transfer rates later reported (Figure S7, 
last column). The UV-visible (UV-vis) spectra of the oxidized and reduced chimeric $\mathrm{CDHs}$ reveal that the $\mathrm{FAD}$ and heme $b$ cofactors are properly incorporated (Figure S2).

Catalytic Performance of DH Domains in Chimeric CDHs. In the reductive half-reaction, the oxidation of cellobiose in the active site of the $\mathrm{DH}$ domain results in the formation of cellobiono- $\delta$-lactone and the reduced cofactor. In the oxidative half-reaction, the two electrons stored at the $\mathrm{FADH}_{2}$ are then transferred to the heme $b$ cofactor in the CYT domain in two separate, one-electron transfer steps to provide electrons for LPMO reduction. ${ }^{7}$ Alternatively, the electrons can be transferred from $\mathrm{FADH}_{2}$ to a two-electron acceptor such as 2,6-dichloroindophenol, which allows the assessment of catalysis without the contribution of the subsequent electron transfer step to the CYT domain. To investigate if the exchange of the CYT domain influences catalysis in the DH domain, we determined the $\mathrm{pH}$ optima, steady-state catalytic constants, and presteady-state rates for the two wild-type $\mathrm{CDHs}$ and the four chimeric CDHs.

The $\mathrm{pH}$-dependence of the catalytic reaction with cellobiose and 2,6-dichloroindophenol resulted in bell-shaped $\mathrm{pH}$ profiles with optima between 4.5 and 5.5 (Figure 2A,B). In comparison with the wild-type enzymes, the chimeric $\mathrm{CDHs}$ show a slight shift of the $\mathrm{pH}$ optimum, narrower peaks, and a reduced activity above $\mathrm{pH}$ 7. The catalytic constants and presteadystate rates were determined at $\mathrm{pH} 6.0$ (Figure 2C and Table $1)$. At this $\mathrm{pH}$, the optimal $\mathrm{CDH}-\mathrm{LPMO}$ interaction was observed, ${ }^{6}$ which is important for IPET experiments. The determined $K_{\mathrm{M}}$ and $k_{\mathrm{cat}}$ of $\mathrm{CDH}_{\mathrm{AAA}}$ for cellobiose are both about four times higher than that of $\mathrm{CDH}_{\mathrm{BBB}}$, which results in the same catalytic efficiency. In the presence of $\mathrm{CYT}_{\mathrm{B}}$, the $K_{\mathrm{M}}$ and $k_{\text {cat }}$ of $\mathrm{DH}_{\mathrm{A}}$ are slightly lower compared to $\mathrm{CDH}_{\mathrm{AAA}}$, whereas the presence of $\mathrm{CYT}_{\mathrm{A}}$ has no significant effect on the $K_{\mathrm{M}}$ and $k_{\text {cat }}$ of $\mathrm{DH}_{\mathrm{B}}$ compared to $\mathrm{CDH}_{\mathrm{BBB}}$. Statistical analysis shows, as expected, a strong correlation between the type of the DH domain and the $k_{\text {cat }}$ for cellobiose, whereas no correlation is found for the influence of the CYT domain on $k_{\text {cat }}$ (Figure S7). The catalytic efficiencies at $\mathrm{pH} 6.0$ are similar for all wild-type and chimeric $\mathrm{CDHs}$, which renders this $\mathrm{pH}$ suitable for studying the subsequent IDET and IPET steps.

The presteady-state reduction rates of $F A D$ at $449 \mathrm{~nm}$ (Figure 2C, $k_{\mathrm{obs}}{ }^{449}$ ) and the extrapolated limiting rates for infinite substrate concentrations (Table $1, k_{\text {lim }}{ }^{449}$ ) show that enzymes with a $\mathrm{DH}_{\mathrm{A}}$ domain oxidized cellobiose $\sim 2.5$ times faster than enzymes with a $\mathrm{DH}_{\mathrm{B}}$ domain but no influence of the swapped CYT domains is observed. A plot of the $k_{\text {obs }}{ }^{449}$ versus the cellobiose concentration indicates a higher substrate affinity of the $\mathrm{DH}_{\mathrm{B}}$ active site, which is in agreement with the results from steady-state analysis. The performed experiments show that the reductive-half reaction of $\mathrm{DH}$ is not affected by a swap of the CYT domain. No bivariate correlation was found between CYT-type and $k_{\text {obs }}{ }^{449}$ in contrast to the high correlation between DH-type and $k_{\text {obs }}$ (Figure S7).

Cofactor Redox Potentials in Chimeric CDH. The FAD and heme $b$ cofactors in $\mathrm{CDH}$ make close contact $(\sim 0.9 \mathrm{~nm}$ edge-to-edge distance) in the enzyme's closed state. To determine if a domain swap influences the redox properties of FAD (Table 1) and heme $b$ (Table 2), the midpoint redox potentials of the wild-type and chimeric $\mathrm{CDHs}$ were measured. However, no significant change was found. The midpoint redox potentials of FAD in all CDHs were between 24 and 43 $\mathrm{mV}$ versus standard hydrogen electrode (SHE). The spectroelectrochemical measurement of the relatively low
Table 2. Steady-State and Transient-State IDET Rates and Heme $b$ Redox Potentials ${ }^{a}$

$\begin{array}{lccc}\text { enzyme } & \text { TN@pH } 6\left[\mathrm{~s}^{-1}\right] & \text { IDET }\left[\mathrm{s}^{-1}\right] & E \text { vs SHE }[\mathrm{mV}] \\ \mathrm{CDH}_{\mathrm{AAA}} & 6.14 \pm 0.12 & 50.00 \pm 0.10 & 102 \pm 4 \\ \mathrm{CDH}_{\mathrm{BAA}} & 0.50 \pm 0.03 & 0.40 \pm 0.02 & 172 \pm 5 \\ \mathrm{CDH}_{\mathrm{BBA}} & 0.04 \pm 0.01 & 0.02 \pm 0.02 & 169 \pm 5 \\ \mathrm{CDH}_{\mathrm{ABA}} & 2.05 \pm 0.01 & 8.42 \pm 0.23 & 110 \pm 2 \\ \mathrm{CDH}_{\mathrm{BBB}} & 1.93 \pm 0.03 & 4.00 \pm 0.01 & 158 \pm 2 \\ \mathrm{CDH}_{\mathrm{ABB}} & 0.48 \pm 0.01 & 0.40 \pm 0.01 & 97 \pm 4 \\ \mathrm{CDH}_{\mathrm{AAB}} & 0.52 \pm 0.01 & 0.40 \pm 0.02 & 103 \pm 4\end{array}$

${ }^{a}$ Comparison of cytochrome $c$ reduction rates (turnover numbers, $\mathrm{TN})$ as an indicator of IDET with transient rates $\left(k_{\mathrm{obs}}{ }^{563}\right)$ at $\mathrm{pH} 6.0$, along the heme $b$ midpoint redox potentials ( $E$ vs SHE).

FAD absorbance in the presence of the strong CYT Soretband resulted in bigger errors for enzyme solutions with a lower enzyme concentration. The low amount of purified $\mathrm{CDH}_{\mathrm{AAB}}$ and $\mathrm{CDH}_{\mathrm{ABA}}$ did not allow the determination of its FAD redox potential. In contrast to the similar redox potential of $\mathrm{FAD}$ in $\mathrm{DH}_{\mathrm{A}}$ and $\mathrm{DH}_{\mathrm{B}}$, the heme $b$ redox potential in the CYT domains differ by about $60 \mathrm{mV}$. While $\mathrm{CYT}_{\mathrm{A}}$ showed little modulation of its redox potential in wild-type and chimeric CDHs $(\sim 97-110 \mathrm{mV}$ vs $\mathrm{SHE})$, the $\mathrm{CYT}_{\mathrm{B}}$ redox potentials were slightly increased (169 and $172 \mathrm{mV}$ vs SHE) in the chimeric CDHs compared to wild-type $\mathrm{CDH}_{\mathrm{BB}}(158 \mathrm{mV}$ vs SHE). However, statistical analysis shows no significant correlation between the type of the DH domain and the CYT midpoint potential (Figure S7).

IDET in Chimeric CDHs. Cellobiose oxidation in the $\mathrm{DH}$ domain is followed by IDET from the $\mathrm{FADH}_{2}$ or FAD semiquinone to the oxidized heme $b$. Steady-state kinetic measurements with cellobiose and the one-electron acceptor cytochrome $c$, which interacts only with CYT but not with the $\mathrm{DH}$ domain, were used to compare wild-type and chimeric CDHs (Figure 3A and Table 2). The cytochrome $c$ turnover number (TN) of $\mathrm{CDH}_{\mathrm{AAA}}$ was about 3.5-fold higher than that of $\mathrm{CDH}_{\mathrm{BBB}}$, which corresponds to the faster catalytic turnover found for $\mathrm{DH}_{\mathrm{A}}$. All chimeric $\mathrm{CDH}$ s exhibit lower cytochrome $c$ TNs than the wild-type CDHs, but it is surprising that for four out of the five chimeric enzymes the decrease is only 3-12fold. Only $\mathrm{CDH}_{\mathrm{BBA}}$ showed an almost complete shutdown but still had a measurable IDET. This indicates two points: (i) the relatively good compatibility of the $\mathrm{DH}$ domains with unfamiliar CYT domains despite their low sequence identity of $42 \%$ and (ii) the influence of the linker on the CYT-DH interaction, which is demonstrated by the reduced IDET of chimeric $\mathrm{CDHs}$ featuring the longer linker $\mathrm{B}_{\mathrm{B}}$. In $\mathrm{CDH}_{\mathrm{ABA}}$, the longer linker reduced the steady-state turnover of cytochrome $c$ by a factor of 3 and the IDET rate by a factor of 19 . The $\mathrm{pH}$ optimum of the IDET was partially influenced by the domain swapping. The wild-type $\mathrm{CDH}_{\mathrm{BBB}}$ has a lower $\mathrm{pH}$ optimum ( $\mathrm{pH} 4.5)$ than $\mathrm{CDH}_{\mathrm{AAA}}$ ( $\mathrm{pH} 5.5$ ) but exhibits a plateau until $\mathrm{pH}$ 8.0. The $\mathrm{pH}$ optima of chimeric $\mathrm{CDHs}$ are identical or close to that of the respective $\mathrm{DH}$ domain, which can be explained by the isoelectric points of the individual domains. The CYT domains in CDH typically have a very low $\mathrm{pI}$ of $\sim 3$, whereas the DH domains have a pI of $\sim 5 .{ }^{19}$ The deprotonation of acidic amino acid residues on the $\mathrm{DH}$ domain close to the CYT-DH interface generates electrostatic repulsion of the strongly negatively charged CYT domain. Interestingly, the plateau observed for $\mathrm{CDH}_{\mathrm{BBB}}$ is also found in $\mathrm{CDH}_{\mathrm{BBA}}$ and $\mathrm{CDH}_{\mathrm{BAA}}$ and thus seems to be a feature of $\mathrm{CYT}_{\mathrm{B}}$. 

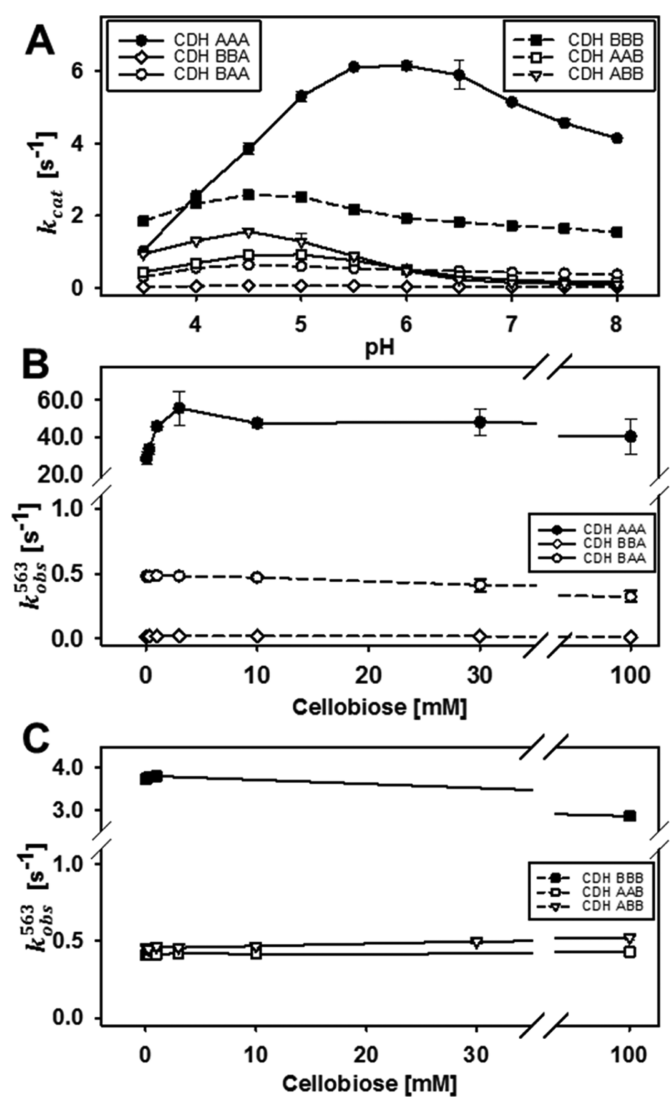

Figure 3. Effects of domain swapping on IDET. (A) $\mathrm{pH}$ optima of cytochrome $c$ turnover numbers for wild-type and chimeric CDHs. (B) IDET rates $\left(k_{\text {obs }}^{563}\right)$ of $\mathrm{DH}_{\mathrm{A}}$ to different CYT domains measured for increasing cellobiose concentrations. (C) IDET rates of $\mathrm{DH}_{\mathrm{B}}$ to different CYT domains measured for increasing cellobiose concentrations.

Although the IPET between CYT and cytochrome $c$ is very fast, $^{20-22}$ it still could influence the observed IDET rate. Therefore, we also measured the transient reduction rate of the heme $b$ cofactor to avoid a possible rate-limiting step. This direct measurement of IDET in $\mathrm{CDH}$ was performed by stopped-flow spectrophotometry at $563 \mathrm{~nm}$ to observe the reduction of the heme $b \alpha$-peak (Figure 3B,C and Table 2). The observed transient rates are consistent with the trend of the steady-state rates with the wild-type $\mathrm{CDHs}$ having the most efficient IDET. The data also show that the cytochrome $c$ assay provides a good estimate for the IDET rate in chimeric $\mathrm{CDH}$ but not for the faster wild-type CDHs. As expected, the IDET rate $\left(k_{\mathrm{obs}}{ }^{563}\right)$ of all CDHs is slower than the respective $\mathrm{FAD}$ reduction rates $\left(k_{\mathrm{obs}}{ }^{449}\right)$. However, in the case of $\mathrm{CDH}_{\mathrm{AAA}}, k_{\mathrm{obs}}{ }^{563}$ is $50 \mathrm{~s}^{-1}$ and very close to $k_{\mathrm{obs}}{ }^{449}\left(80 \mathrm{~s}^{-1}\right)$. In this case, IDET is limited at low cellobiose concentrations $(<1 \mathrm{mM})$. For $\mathrm{CDH}_{\mathrm{BBB}}$ and all chimeric $\mathrm{CDHs}$, a much slower IDET was observed and, therefore, a limitation was found only for substrate concentrations below $50 \mu \mathrm{M}$. Considering that the redox potential difference between $\mathrm{CYT}_{\mathrm{A}}$ and $\mathrm{DH}_{\mathrm{A}}(\sim 102$ $\mathrm{mV})$ is lower than for $\mathrm{CYT}_{\mathrm{B}}$ and $\mathrm{DH}_{\mathrm{A}}$ or $\mathrm{DH}_{\mathrm{B}}(\sim 158 \mathrm{mV})$, the thermodynamic driving force between the cofactors is obviously irrelevant for the IDET rate. Also, no statistical correlation was observed between the midpoint redox potential and IDET rate (Figure S7). This exciting observation was further investigated by calculating the electron transfer rate based on the Marcus theory of electron tunneling. A modified version used by Dutton and coworkers ${ }^{23,24}$ was applied using reported maximum, average, and minimum values for the quantum mechanical constants $(\lambda, B, E)$ for the calculation of the corresponding distance-dependent electron transfer rates. The average edge-to-edge distance between the $\mathrm{FAD}$ and the heme $b$ propionate $\mathrm{A}$ in docking models of $\mathrm{CDH}_{\mathrm{AAA}}$ and $\mathrm{CDH}_{\mathrm{BBB}}$ was found to be $0.9 \mathrm{~nm}$, respectively (Figure 4). This corresponds to theoretical IDET rates in the order of $10^{5}$ to $10^{6} \mathrm{~s}^{-1}$, which are at least four orders of magnitude faster than the measured IDET rates.

Considering the observed mobility of the linker and CYT domain in $\mathrm{CDH}$, we postulate that this large difference between the calculated and the measured rates is because of conformational changes: the transition between the open- and
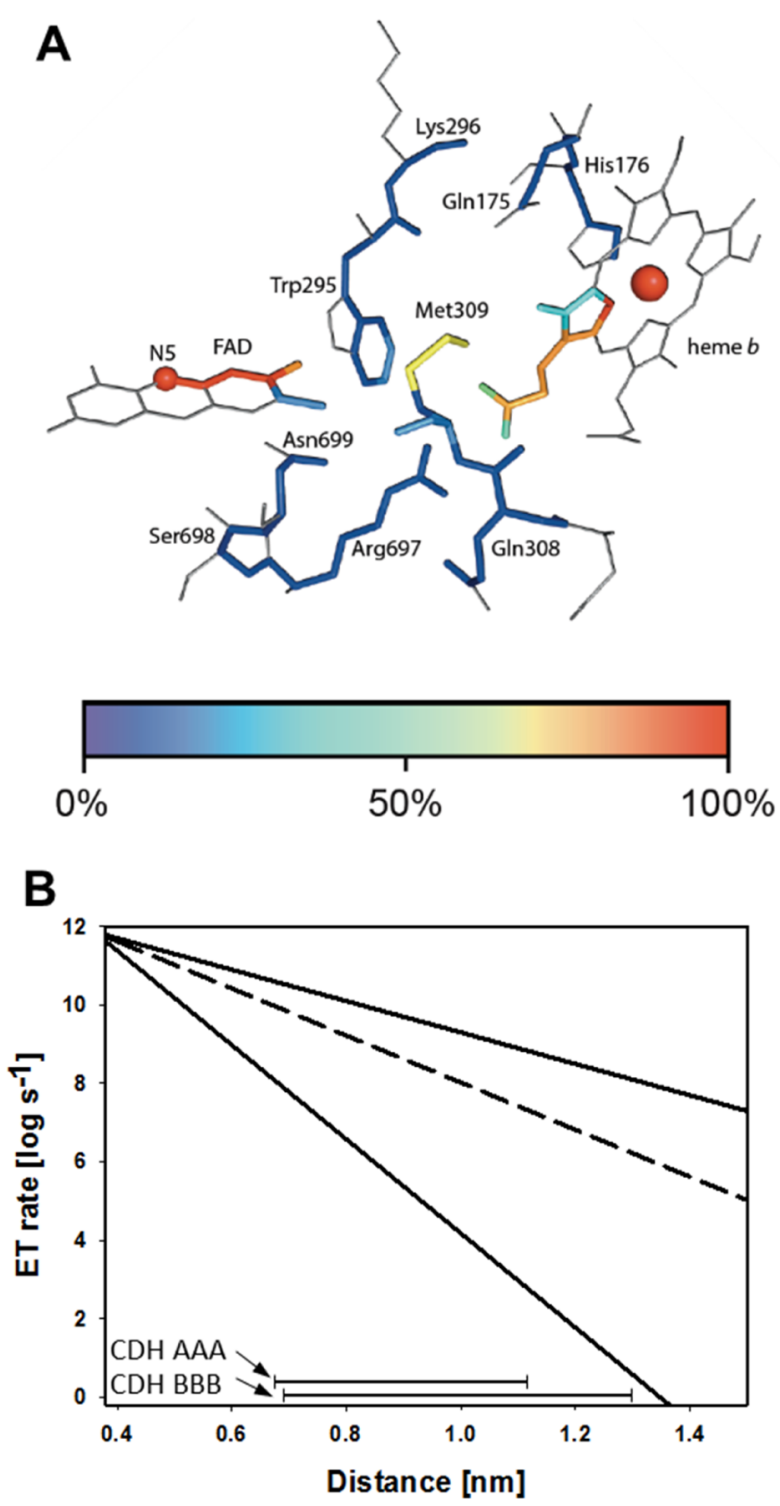

Figure 4. Electron transfer in CDH (IDET). (A) Detail of the crystal structure of MtCDHIIA (PDB: 4QI6) featuring the closed-state conformation. The edge-to-edge distance between the $\mathrm{FAD}$ and heme cofactors is $0.9 \mathrm{~nm}$. (B) Electron transfer rate plotted against cofactor distance for $\mathrm{CDH}$ (lower and upper limit, solid lines; most probable parameters, dashed line). The bars at the bottom indicate the observed IDET rates and edge-to-edge distances for $\mathrm{CDH}_{\mathrm{AAA}}$ and $\mathrm{CDH}_{\mathrm{BBB}}$ in docking calculations. 


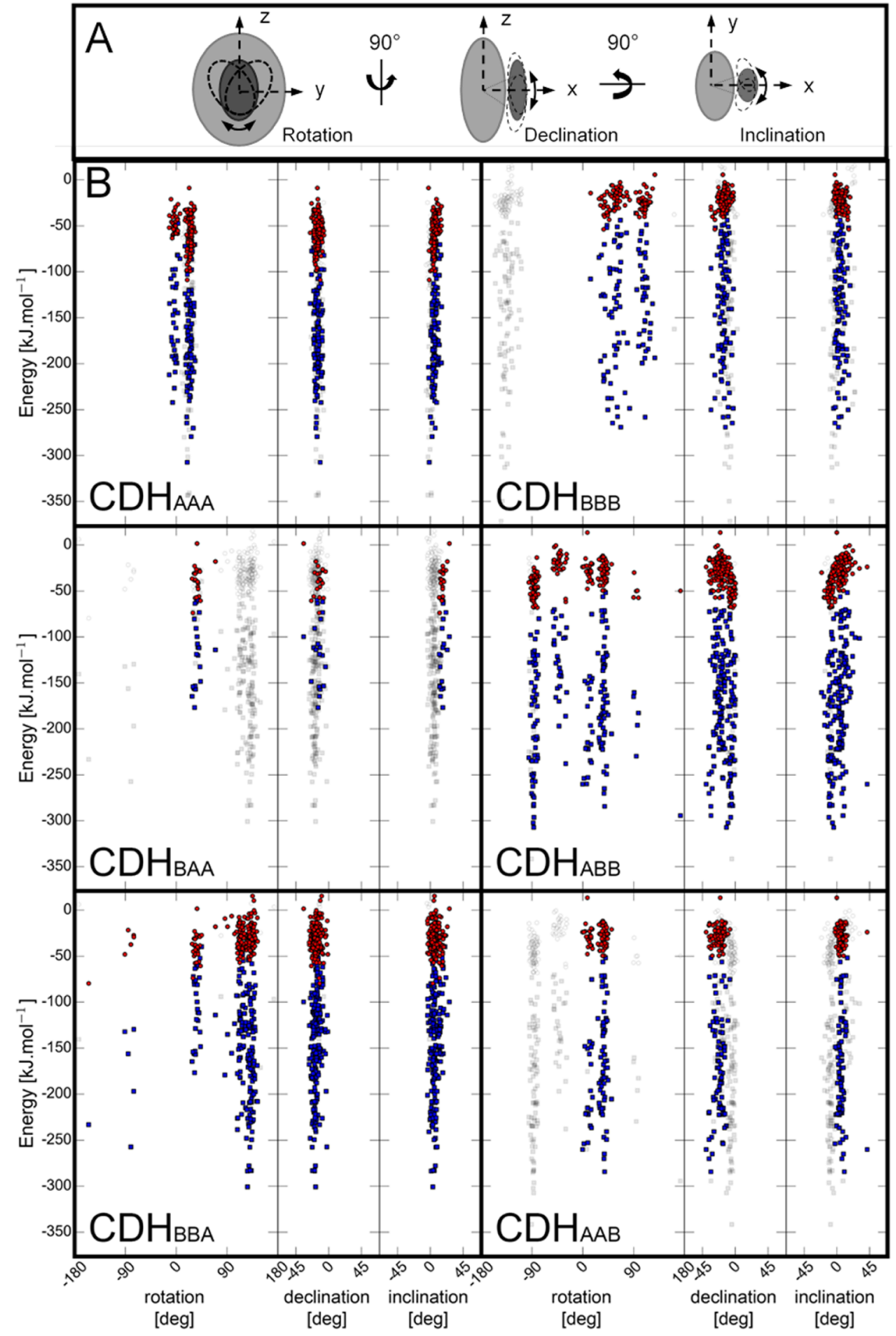

Figure 5. Orientation of CYT to DH in docking poses. (A) Schematic representation of evaluated angles. (B) From a total of 200 docking poses for each CYT-linker-DH pair the angle of rotation, declination, and inclination were measured in regard to its deviation from the crystal structure of the closed-state conformation of M. thermophilum CDH (PDB ID: 4QI6). The electrostatic (red) and van der Waals (blue) binding energies for each pose are given in $\mathrm{kJ} \mathrm{mol}^{-1}$. Docking poses in wild-type $\mathrm{CDH}_{\mathrm{AAA}}$ and wild-type $\mathrm{CDH}_{\mathrm{BBB}}$ are compared to docking poses of chimeric $\mathrm{CDH}_{\mathrm{BAA}}$ $\mathrm{CDH}_{\mathrm{ABB}}, \mathrm{CDH}_{\mathrm{BBA}}$ and $\mathrm{CDH}_{\mathrm{AAB}}$.

closed states of the $\mathrm{CDH}$. The optimal, closest possible distance between the $\mathrm{FAD}$ and heme $b$ cofactors depends on the correct orientation of the CYT domain at its $\mathrm{DH}$ domain interface. The open-state distance between the cofactors can easily exceed $1.5 \mathrm{~nm}$ and shut down IDET. With IDET depending on the closed state or at least very close proximity between $\mathrm{DH}$ and CYT, a steric mismatch between the domain surfaces, repulsive electrostatic interactions, or a linker that provides too much mobility will reduce IDET. This is supported by the inspection of the $k_{\mathrm{obs}}{ }^{563}$ rates for both evolved wild-type CDHs and the chimeric CDHs (Table 2). The IDET for the constructed chimeric enzymes decreased by one order of magnitude for $\mathrm{CDH}_{\mathrm{AAB}}, \mathrm{CDH}_{\mathrm{ABB}}$, and $\mathrm{CDH}_{\mathrm{ABA}}$, two orders of magnitude for $\mathrm{CDH}_{\mathrm{BAA}}$ and three orders of 


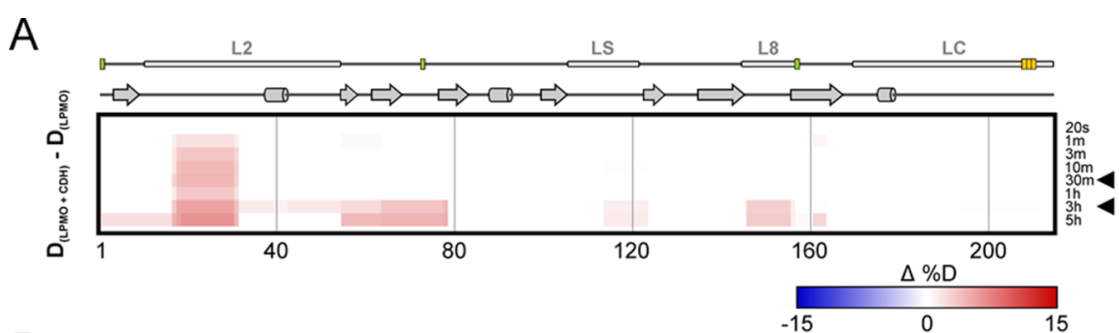

B

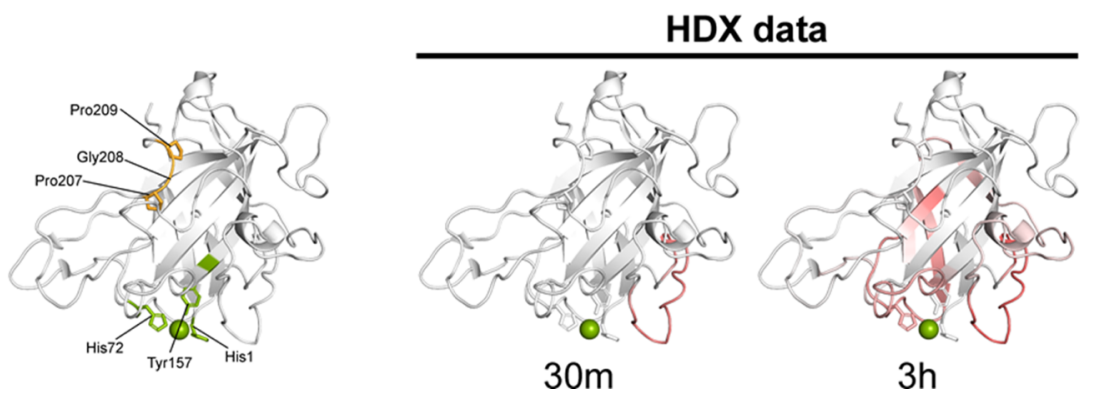

Figure 6. Structure dynamics arising from $N$. crassa LPMO9F and $\mathrm{CDH}_{\mathrm{AAA}}$ interaction detected by H/D exchange. Structural differences between free LPMO and LPMO in the presence of $\mathrm{CDH}_{\mathrm{AAA}}$ were visualized using a difference heat map (A) (http://peterslab.org/MSTools/). Deuteration levels of the protein alone were subtracted from those observed for the protein in the presence of $\mathrm{CDH}_{\mathrm{AAA}}$. Increased deuteration (deprotection) upon interaction is shown by red colors while protection is in blue (scale bar is at the bottom of the panel). Secondary structure elements, loops, and copper coordinating residues (green) and ProGlyPro patch (orange) are depicted above the heat map. Individual exchange times are shown on the right. Two selected time points ( $30 \mathrm{~min}$ and $3 \mathrm{~h}$, indicated by arrowhead) were visualized on the LPMO structure (PDB ID: 4QI8) (B). The coloring scale follows the one in panel A. The central copper atom is shown in green and the side chains of the histidine brace residues and ProGly-Pro patch are shown as sticks. The structure on the left visualizes histidine brace (green) and Pro-Gly-Pro patch (orange) residues.

magnitude for $\mathrm{CDH}_{\mathrm{BBA}}$. In the case of $\mathrm{CDH}_{\mathrm{ABA}}$, in which the $\mathrm{CYT}_{\mathrm{A}}-\mathrm{DH}_{\mathrm{A}}$ interface is not altered, the longer linker results in an only 19 times lower IDET compared to the 125 times reduction of $\mathrm{CDH}_{\mathrm{BAA}}$ in which the CYT domain is swapped.

Based on the steady-state catalytic constants and $k_{\text {obs }}{ }^{563}$, a limiting substrate concentration, above which the IDET confines the catalytic rate, can be calculated. For the naturally

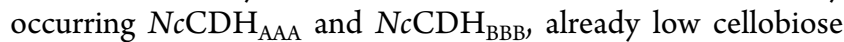
concentrations ( 55 and $35 \mu \mathrm{M}$, respectively) ensure that both $\mathrm{CDH}$ s reach their maximum IDET rate, which is the prerequisite of efficient LPMO reduction.

Evaluation of the DH-CYT Interaction Site by Docking. The program HADDOCK $\mathrm{H}^{25,26}$ was used to determine the interface of the four possible CYT-DH combinations found in the wild-type and chimeric enzymes by ambiguous restraint driven docking. A sample size of 200 docking poses for each CYT-DH pair was used for analysis. A "rotation" angle is used to define the rotation of CYT around a defined interdomain axis (Figure 5A and Table S2) in regard to $\mathrm{DH}$, relative to the corresponding angle observed in the closed state of the Myriococcum thermophilum $\mathrm{CDH}$ structure (PDB ID: 4QI6). Similarly, we used the terms "declination" to describe the vertical offset angle and "inclination" to describe the horizontal offset angle of the docked CYT domain relative to the $\mathrm{DH}$ domain. The feasibility of docking poses was further assessed by considering the maximal extension of $\operatorname{linker}_{\mathrm{A}}$ and linker $_{B}$, which was estimated to be 6 and $11 \mathrm{~nm}$, respectively. By using the distance field reaction coordinate as implemented in GROMOS++ software, ${ }^{27,28}$ the shortest curved distance between the C-terminus of the CYT domain and the $\mathrm{N}$ terminus of the $\mathrm{DH}$ domain not passing through the protein was computed. Docking poses, in which this distance was longer than the maximal extension of the linker, were excluded from subsequent analysis (Figure $5 \mathrm{~B}$, grey squares). The $\mathrm{pH}$ - dependent surface charges of the domains were calculated from $\mathrm{pH} 4-8$ (Figure S3) and the protonation states corresponding to $\mathrm{pH} 6.0$ were used for the docking. For this $\mathrm{pH}$, the contribution of the van der Waals energy to the proteinprotein interaction $\left(-158.14 \pm 62.2 \mathrm{~kJ} \mathrm{~mol}^{-1}\right)$ is generally 45 times higher than the electrostatic energy $(-36.79 \pm 20.9 \mathrm{~kJ}$ $\mathrm{mol}^{-1}$ ), which indicates the importance of structurally complementary domain surfaces. A comparison of $\mathrm{CDH}_{\mathrm{AAA}}$ and $\mathrm{CDH}_{\mathrm{BBB}}$ shows that the declination and inclination angles of the 200 docking positions are narrower for $\mathrm{CDH}_{\mathrm{AAA}}$, which is indicative of a sterically more defined CYT-DH interaction. In $\mathrm{CDH}_{\mathrm{AAA}}$ the CYT rotation around the rotation axis is well defined by two groups with angles at $-5 \pm 15$ and $25 \pm 15^{\circ}$. The rotational position at $19.5^{\circ}$ is preferred because it exhibits the strongest van der Waals and electrostatic interaction energies. In $\mathrm{CDH}_{\mathrm{BBB}}$, the docked rotational positions fall further apart $\left(40 \pm 50,110 \pm 20^{\circ}\right)$, indicating a less directed interaction and a lower complementarity of the domain surfaces. The interaction energies are less favorable than in $\mathrm{CDH}_{\mathrm{AAA}}$. Interestingly, the energetically most favorable docking position of CYT and $\mathrm{DH}$ in $\mathrm{CDH}_{\mathrm{BBB}}$ is not feasible because of the restricting length of the linker. This particular position with a rotation angle of $-144.5^{\circ}$ corresponds to an almost $180^{\circ}$ rotation of the allowed rotational position with the second lowest van der Waals energy.

In chimeric $\mathrm{CDH}$, the linker plays an important role. The shorter linker $_{\mathrm{A}}$ restricts the angular CYT orientation in $\mathrm{CDH}_{\mathrm{BAA}}$ and $\mathrm{CDH}_{\mathrm{AAB}}$ much more than the longer linker ${ }_{\mathrm{B}}$ in $\mathrm{CDH}_{\mathrm{BBA}}$ and $\mathrm{CDH}_{\mathrm{ABB}}$. Only one angular orientation at $45 \pm$ $25^{\circ}$ is allowed by the length of linker ${ }_{A}$, while the longer linker ${ }_{B}$ allows for rotational positions between $45 \pm 25$ and $110 \pm 40^{\circ}$. In the case of $\mathrm{CDH}_{\mathrm{BBA}}\left(k_{\mathrm{obs}}^{563}=0.04 \mathrm{~s}^{-1}\right)$, the rotational orientation of $\mathrm{CYT}_{\mathrm{B}}$ against $\mathrm{DH}_{\mathrm{A}}$ at $126.3^{\circ}$ is strongly preferred in terms of interaction energies $\left(E_{\mathrm{vdW}}\right.$ : $-300.7 \mathrm{~kJ}$ 
$\mathrm{mol}^{-1} ; E_{\text {Elec }}-40.4 \mathrm{~kJ} \mathrm{~mol}^{-1}$ ) over rotational position at $32.7^{\circ}$ (which is the IDET competent orientation in $\mathrm{CDH}_{\mathrm{BAA}}$ ), which has less favorable interaction energies $\left(E_{\mathrm{vdW}}:-176.8 \mathrm{~kJ} \mathrm{~mol}^{-1}\right.$; $E_{\text {Elec }}$ : $\left.-22.8 \mathrm{~kJ} \mathrm{~mol}^{-1}\right)$. The steric restriction provided by linker $_{\mathrm{A}}$ prevents the $\mathrm{CYT}$ in $\mathrm{CDH}_{\mathrm{BAA}}$ to bind in a noncompetent position and thereby increases IDET $\left(k_{\mathrm{obs}}{ }^{563}\right.$ $\left.=0.4 \mathrm{~s}^{-1}\right)$.

The average contact surface area for all possible complexes was calculated and averaged for each CYT-DH combination as well as the binding affinity using PRODIGY ${ }^{29-31}$ (Table S3). The averaged contact surface areas correspond to $\sim 4 \%$ of the total DH surface area and $\sim 9 \%$ of the total CYT surface area. The small interaction site and low calculated affinities of the CYT-DH complexes $\left(K_{\mathrm{D}}=3.2-47 \mu \mathrm{M}\right)$ suggest a relatively transient and reversible interaction when compared to other redox proteins. ${ }^{32}$

Interaction Site of CYT with LPMO. Two interaction sites on CDH's CYT domain with LPMO have been proposed in the literature based on computational docking. One potential interaction site has been proposed to be opposite to LPMO's type- 2 copper center around a conserved Pro-GlyPro patch, ${ }^{33}$ which requires long-range electron transfer through LPMO but would allow the reduction of the substrate-bound LPMO. Another study suggested a direct interaction of heme $b$ in CYT with the copper center of LPMO, which would necessitate the desorption of LPMO from its polymeric substrate. This mode would require no long-range electron transfer through the LPMO molecule. ${ }^{9}$ To experimentally determine the protein-protein interaction site of $\mathrm{CDH}$ and LPMO in solution, H/D exchange kinetics were followed by mass spectrometry for $\mathrm{CDH}_{\mathrm{AAA}}$ and $\mathrm{N}$. crassa LPMO9F. This particular LPMO is well suited for such an analysis because it is relatively small $(24.8 \mathrm{kDa})$ and lacks $N$ glycosylation, a C-terminal CBM1, and the linker region, which is often heavily $O$-glycosylated. ${ }^{34}$

Both proteins alone or in a mixture were subjected to H/D exchange followed by online digestion with pepsin and the resulting fragments were analyzed as described previously. ${ }^{32}$ No detectable difference in the deuteration was observed on $\mathrm{CDH}_{\mathrm{AAA}}$. This could be caused by a combination of several factors: (i) a very short-lived or weak interaction of both enzymes, (ii) the protruding heme propionate-A group being the most prominent interaction partner leading to little involvement of other CYT residues, or (iii) the subsequent CYT-DH interaction interfering with the CYT deuteration.

For LPMO9F, on the other hand, protein backbone deprotection was observed in several peptide fragments when $\mathrm{CDH}$ was present in the solution. Visualization on the crystal structure (PDB ID: 4QI8) ${ }^{9}$ shows that the perturbed protein regions occur in three loops surrounding the active site copper center (Figure 6). Although deprotection by the interaction is not the most common scenario in $\mathrm{H} / \mathrm{D}$ exchange, it has been recognized as one of the possible biologically relevant outcomes. $^{35-37}$ In the case of CDH-LPMO interaction, it likely reflects the transient nature of the complex, where a short-lived interaction with the heme $b$ in CYT leads to the local loosening of the structure around the copper center of LPMO and/or destabilization of the hydrogen bonding network in this region. Finally, no deuteration changes of any kind were observed around the conserved patch ${ }^{207}$ ProGly-Pro $^{209}$ (Figure 6) close to the C-terminus.

Heterogenous Electron Transfer. $\mathrm{CDH}$ is recognized for its ability to directly transfer electrons to electrode surfaces via its CYT domain. ${ }^{38}$ The heterogeneous electron transfer of wild-type and chimeric $\mathrm{CDHs}$ to a self-assembled monolayer (SAM) of thioglycerol on gold electrodes ${ }^{7}$ was investigated for two reasons: (i) to verify that all produced enzymes and their domains are in their native, electron transfer competent conformation and (ii) to study the effect of swapped linkers and CYT domains on the direct electron transfer to an electrode. Unfortunately, $\mathrm{CDH}_{\mathrm{BBA}}$ was not available in sufficient amounts for these experiments. In the presence of $20 \mathrm{mM}$ cellobiose, catalytic currents were observed for all variants (Figure S4). The onset potentials of the anodic waves correlate well with the corresponding, spectroelectrochemically determined CYT redox potentials. Current densities were extracted at an overpotential of $200 \mathrm{mV}$, above the midpoint potential of the CYT domain $\left(\mathrm{CYT}_{\mathrm{A}}\right.$ at $300 \mathrm{mV}, \mathrm{CYT}_{\mathrm{B}}$ at 360 $\mathrm{mV}$ vs SHE) and a scan rate of $15 \mathrm{mV} \mathrm{s}^{-1}$. The highest current density was found for $\mathrm{CDH}_{\mathrm{AAA}}\left(11.3 \pm 1.8 \mu \mathrm{A} \mathrm{cm}^{-2}\right)$, followed by $\mathrm{CDH}_{\mathrm{ABB}}\left(3.7 \pm 1.5 \mu \mathrm{A} \mathrm{cm} \mathrm{cm}^{-2}\right), \mathrm{CDH}_{\mathrm{BBB}}(2.6 \pm 1.7 \mu \mathrm{A}$ $\left.\mathrm{cm}^{-2}\right), \mathrm{CDHB}_{\mathrm{BAA}}\left(1.9 \pm 0.3 \mu \mathrm{A} \mathrm{cm}^{-2}\right)$, and $\mathrm{CDH}_{\mathrm{AAB}}(1.2 \pm$ $\left.1.0 \mu \mathrm{A} \mathrm{cm}{ }^{-2}\right)$. Every $\mathrm{CDH}$ clearly showed direct electron transfer to the electrode and thereby verified the integrity of the electron transfer route.

Anodic and cathodic peak currents were obtained for all CDHs over a range of scan rates $\left(3-150 \mathrm{mV} \mathrm{s}^{-1}\right)$. The plot of the peak currents versus the square root of the scan rates is linear for all enzymes and indicate a freely diffusing redox species and no adsorption onto the electrode (Figure S5). The peak separation of the anodic and cathodic peak increased with increasing scan rates (Figure S6). The heterogeneous electron transfer is reversible at very low scan rates and quasi-reversible at scan rates above $5 \mathrm{mV} \mathrm{s}^{-1}$, pointing toward a fast electron transfer compared to mass transport. This allows the calculation of the heterogeneous electron transfer constant $\left(k^{0}\right)$ according to the method of Nicholson and Shain for the quasi-reversible electron transfer regime. ${ }^{39}$ All wild-type and chimeric CDHs show a similar $k^{0}$ between 7.7 and $17.7 \times 10^{-4}$ $\mathrm{cm} \mathrm{s}^{-1}$ at the most relevant scan speed for comparison $(50 \mathrm{mV}$ $\mathrm{s}^{-1}$, Figure 7 ), which demonstrates that there is no restrained interaction of any CYT with the thioglycerol monolayer on the gold electrode and all $\mathrm{CDH}$ variants are functional. This is

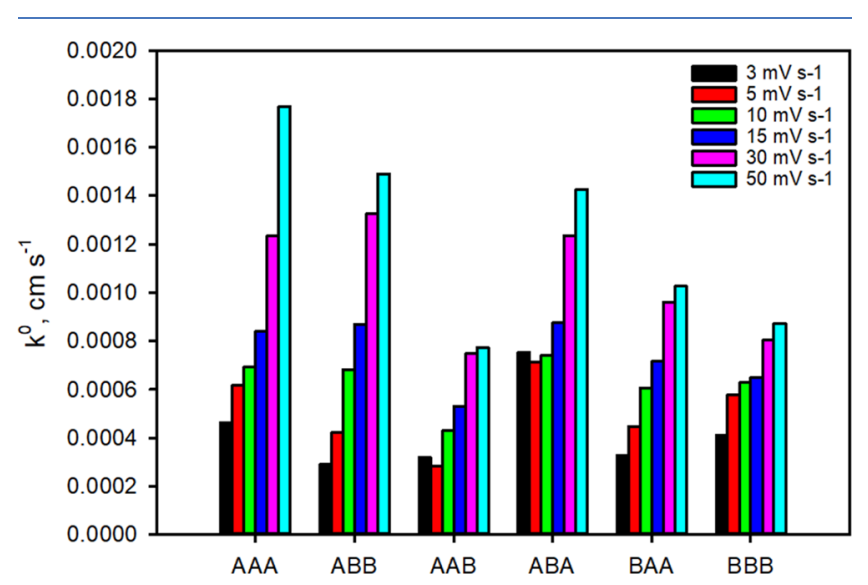

Figure 7. Heterogeneous electron transfer rates $\left(k^{0}\right) \cdot k^{0}$ was calculated from the peak separation of the anodic and cathodic wave observed from cyclic voltammograms measured at different scan rates $3-50$ $\mathrm{mV} \mathrm{s}^{-1}$ ) according to Nicholson-Shain. Data from scan rates above $50 \mathrm{mV} \mathrm{s}^{-1}$ could not be used because the increased capacitive current did not allow the exact determination of the peak maxima. The data (peak separation vs scan rate) are given in Figure S6. 
comparable with a $k^{0}$ of ca. $10^{-3}$ to $10^{-4} \mathrm{~cm} \mathrm{~s}^{-1}$ for cytochrome $c$ on gold electrodes. ${ }^{40} \mathrm{CDH}_{\mathrm{BBB}}$ with the lowest $k^{0}$ has the least efficient electron transfer of its CYT domain with the electrode.

IPET Kinetics. After verifying that the wild-type and chimeric CDHs are all electron transfer competent, we investigated the final electron transfer from CYT to LPMO (IPET). In sequential stopped-flow experiments, CDHs were prereduced by a stoichiometric amount of cellobiose. After 90 $\mathrm{s}$ in the aging loop, oxygen had fully reoxidized the $\mathrm{FADH}_{2}$, which was necessary to prevent any interfering IDET to CYT. Then, the $\mathrm{CDH}$ with the reduced CYT was shot against an equimolar, 3-, 10-, and a 50-fold molar ratio of NcLPMO9C to measure the IPET rate. A linear dependence of $k_{\text {obs }}^{563}$ on LPMO concentrations was found (Figure 8), which indicates

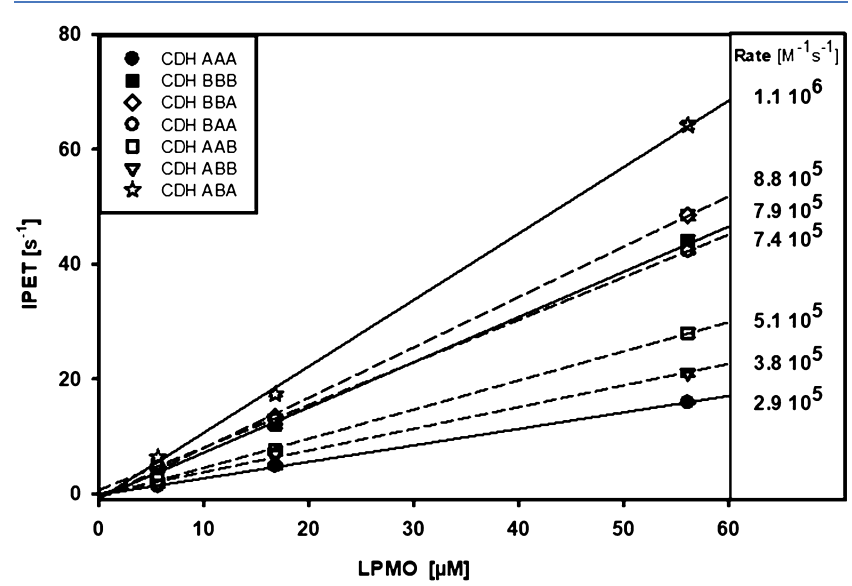

Figure 8. Effects of domain swapping on IPET. Stopped-flow measurements of the electron transfer from prereduced CYT to LPMO at $563 \mathrm{~nm}$ at for increasing LPMO concentrations show a linear relation from which bimolecular rates were calculated.

that the electron transfer between both enzymes is fast enough to show no saturation even for the highest measured LPMO concentration. $^{21}$ The bimolecular IPET rate was calculated from the slope of $k_{\mathrm{obs}}{ }^{563}$ versus the LPMO concentration. The determined rates are all within the same order of magnitude, which indicates that the interaction mechanism is not evolved to recognize and favor specific $\mathrm{CDH}-\mathrm{LPMO}$ combinations but is based on a universal recognition mechanism which depends little on surface complementarity. The observed differences in IPET show that $\mathrm{CYT}_{\mathrm{B}}$, which is present in three measured CDHs, exhibit a two times faster bimolecular rate with NcLPMO9C $\left(7.4-8.8 \times 10^{5} \mathrm{M}^{-1} \mathrm{~s}^{-1}\right)$ than most CDHs with $\mathrm{CYT}_{\mathrm{A}}\left(2.9-5.1 \times 10^{5} \mathrm{M}^{-1} \mathrm{~s}^{-1}\right)$ with the exception of $\mathrm{CDH}_{\mathrm{ABA}}$, which exhibits the highest IPET rate. This points toward the importance of the linker and its influence on the closed- and open-state conformation. $\mathrm{CDH}_{\mathrm{AAA}}$ with the short linker, the fastest IDET, and the slowest IPET prefers the closed-state conformation, whereas $\mathrm{CDH}_{\mathrm{BBA}}$ or $\mathrm{CDH}_{\mathrm{ABA}}$ with reduced IDET and fast IPET prefer the open-state conformation.

In contrast, a higher redox potential difference between the $\mathrm{CDH}$ and LPMO cofactors has not the expected, rate enhancing effect on the IPET rate (Table 2, Figure 8). $\mathrm{CYT}_{\mathrm{B}}$ with its $\sim 60 \mathrm{mV}$ higher midpoint potential compared to $\mathrm{CYT}_{\mathrm{A}}$ has a comparatively lower driving force for electron transfer between the heme $b$ and LPMO's type- 2 copper but shows similar IPET rates to $\mathrm{CYT}_{\mathrm{A}}$. This indicates that CYT-
DH combinations of poor surface complementarity or with an unsuitable linker preferably populate the IPET competent open-state conformation. We conclude that the closed- and open-state distribution of $\mathrm{CDH}$ populations define the electron transfer rates of CYT in IDET and IPET.

Multivariate Analysis. Mixed factor principal component analysis (PCA), including the quantitative variables $\left(k_{\mathrm{cat}}, k_{\mathrm{obs}}\right.$, IDET, IPET, CYT midpoint redox potential, and glycosylation) and qualitative variables [DH-, CYT-, and linker-type (Tables S5 and Figure S9)], has been performed on the data set from wild-type and chimeric $\mathrm{CDHs}$ to explore intercorrelation. Glycosylation shows the smallest effect of all quantitative variables, while the kinetic variables cluster as expected from bivariate analysis.

\section{DISCUSSION}

The two-domain structure of $\mathrm{CDH}$ has been recognized soon after its discovery, by observing the spectral features of its two cofactors, proteolytic cleavage into the separated domains, and distinct catalytic properties of the full-length $\mathrm{CDH}$ and its $\mathrm{DH}$ domain. The domain organization became evident with the first isolated $\mathrm{CDH}$ sequence of Phanerochaete chrysosporium, ${ }^{41}$ but the purpose of the CYT domain remained unknown. Crystallization experiments in which only the separated, proteolytically generated CYT and DH domains formed crystals indicated the high mobility of the linker and CYT domain. ${ }^{18,42}$ At the same time, Igarashi et al. investigated the $\mathrm{pH}$ dependence of the IDET between the $\mathrm{DH}$ and CYT domains of $P$. chrysosporium $\mathrm{CDH}$ in a presteady-state kinetic study. He also determined the redox potentials of the heme $b$ and FAD cofactor, which can influence IDET. ${ }^{10}$

However, the physiological function of the CYT domain and the highly variable length of the linker in CDHs (16-40 amino acids) remained enigmatic. Also, the considerable length of linker ${ }_{\mathrm{B}}$ in comparison to other flavocytochromes, for example, the flavocytochrome $b_{2}$ 's hinge (linker) region consisting of only 15 amino acids, ${ }^{43}$ is unusual. In the two CDHs from $N$. crassa, linker $\mathrm{B}_{\mathrm{B}}$ is almost twice as long as linker ${ }_{\mathrm{A}}$. Both enzymes have the lowest sequence identity (29\%) among CDH's structural elements despite sharing two common features: a high percentage of serine, threonine, and proline residues and a conserved Pro-Val-Pro motif. Likewise, the sequence identity among the CYT domains (43\%) is low compared to that of the DH domains (60\%). The higher diversity of the linker and CYT sequences is observed for all CDHs and suggests an evolutionary adaptation to contact various redox partner proteins, while the $\mathrm{DH}$ domain serves as a source of electrons.

With the discovery of LPMO in $2010,{ }^{44}$ the physiological redox partner of $\mathrm{CDH}$ was finally revealed, which gives us the opportunity to study the CYT domain's IDET and IPET mechanism as part of a natural, extracellular electron transfer chain. This framework allows the testing of hypotheses on $\mathrm{CDH}$ 's molecular, catalytic, and electron transfer properties. Swapping domains between the structurally, catalytically and electrochemically different $\mathrm{CDHs}$ of one organism allows differentiating between the functions of the involved domains and linkers in the electron transfer route from $\mathrm{CDH}^{\prime}$ ' $\mathrm{FADH}_{2}$ to LPMO's type-2 copper center. Two wild-type and five chimeric $\mathrm{CDHs}$ could be recombinantly expressed in $P$. pastoris and all enzymes except $\mathrm{CDH}_{\mathrm{AAB}}$ and $\mathrm{CDH}_{\mathrm{BBA}}$ could be produced in quantities above $10 \mathrm{mg}$, sufficient for a full set of analysis. The specific activities of the purified chimeric enzymes and their absorption spectra are in consonance with 
the wild-type CDHs and, therefore, these enzymes are properly folded. However, a difference in the extent of glycosylation of the wild-type and chimeric CDHs was found. This variation is inevitable with the chosen yeast expression system, which is known to produce various glycoforms. However, the $\mathrm{N}$ glycosylation sites are not located at the DH-CYT interface and thus should not affect the experiments. O-Glycosylation of the linker was previously reported, ${ }^{45}$ but we lacked the resources to determine if this minor fraction of glycosides varied between the produced CDHs. However, the determined heterogeneous electron transfer rates for all $\mathrm{CDHs}$ were relatively similar and indicated no significant influence of the glycosylation on the interaction with the thioglycerol-modified gold electrode.

Transient kinetic studies of the catalytic reaction of the $\mathrm{DH}$ domain showed no change of the reductive half-reaction in chimeric CDHs but showed an effect of the swapped CYT domains on the oxidative half-reaction by shifting the $\mathrm{pH}$ optima for the two-electron acceptor 2,6-dichloroindophenol. The $\mathrm{pH}$ optima of $\mathrm{CDH}_{\mathrm{AAA}}$ and $\mathrm{CDH}_{\mathrm{BBB}}$ are identical to previous data. ${ }^{7}$ Because the $\mathrm{pH}$ optimum of the catalytic reaction in $\mathrm{CDH}$ generally depends on the electron acceptor, ${ }^{19,46}$ this indicates an impact of the CYT domain on the oxidative catalytic half-reaction. These results support the previously observed effect of the CYT domain on the catalytic step in the DH domain of Crassicarpon hotsonii (syn. M. thermophilum) $\mathrm{CDH}^{11}$ At $\mathrm{pH}$ 6.0, which is also the $\mathrm{pH}$ optimum of the CDH-LPMO interaction, ${ }^{6}$ only small differences between the catalytic efficiencies were observed between the wild-type and chimeric $\mathrm{CDHs}$, rendering this $\mathrm{pH}$ as suitable to study the subsequent electron transfer steps. The presteady-state reduction rates of FAD by cellobiose at $449 \mathrm{~nm}$ $\left(k_{\mathrm{obs}}{ }^{449}\right)$ show a clear separation between enzymes with a $\mathrm{DH}_{\mathrm{A}}$ domain $\left(80-89 s^{-1}\right)$ and $a \mathrm{DH}_{\mathrm{B}}$ domain $\left(30-33 \mathrm{~s}^{-1}\right)$ but no effect of a CYT swap on the rate of the reductive-half reaction.

While the effects of the domain swap on the catalysis of the chimeric enzymes were moderate, the IDET between DH and CYT was strongly affected. Steady-state experiments showed different $\mathrm{pH}$ optima and 3-12 times (except for $\mathrm{CDH}_{\mathrm{BBA}}$ ) reduced TN's of the chimeric $\mathrm{CDH}$ s with cytochrome $c$. These findings were corroborated by transient-state data. The highest IDET rates were measured for wild-type enzymes, which had a 19 times $\left(\mathrm{CDH}_{\mathrm{AAA}}\right)$ or 10 times $\left(\mathrm{CDH}_{\mathrm{BBB}}\right)$ higher IDET rate than the successive chimeric $\mathrm{CDH}$. Modeling studies showed the importance of surface complementarity and the degree of orientational freedom provided by the linker. Given the varying length of $\operatorname{linker}_{\mathrm{A}}(7 \mathrm{~nm})$ and $\operatorname{linker}_{\mathrm{B}}(11 \mathrm{~nm})$, it can be expected that in the open state the distance limit for a reasonable fast electron transfer $(\sim 1.5 \mathrm{~nm})$ between CYT and $\mathrm{DH}$ is often exceeded. It was also found that the redox potential difference between $\mathrm{CYT}$ and $\mathrm{DH}$ is not the dominant driving force for IDET because $\mathrm{CDH}$ with a $\mathrm{CYT}_{\mathrm{A}}$ have a lower $\Delta E(64-104 \mathrm{mV})$ between the cofactors than $\mathrm{CYT}_{\mathrm{B}}$ carrying CDHs $(158-172 \mathrm{mV})$ but similar or faster IDET rates. The reason is the close edge-to-edge distance between the FAD and heme. For the typical distance of $\sim 0.9 \mathrm{~nm}$ in $N$. crassa CDH's closed state, the electron transfer rates are $10^{5}$ times higher than the measured rates. This suggests that the mobility of the CYT domain and its shift between closed- and open-state conformations is the rate-limiting factor of IDET, rather than the electron transfer event itself. A shorter linker $\left(\right.$ linker $\left._{\mathrm{A}}\right)$ and a higher complementarity at the CYT-DH interface increases IDET by supporting the closed state of the $\mathrm{CDH}$.

The efficiency of the subsequent electron transfer step from CYT to LPMO, the IPET, is most important for the efficiency of the process and determines the rate of LPMO reduction. A specific and fast IPET saves valuable resources for the metabolism of the cellulolytic organism (less enzymatic consumption of cellobiose, less secreted $\mathrm{CDH}$ needed) and prevents futile electron transfer to other electron acceptors or scavengers, which reduces not only the efficiency of the extracellular electron transfer system but could also produce degradation products detrimental to the organism's growth. The HDX-MS experiments showed the interaction of CYT and LPMO to happen via direct contact between their active centers. This is in agreement with NMR and docking studies. ${ }^{15,16}$ No alternative interaction site of CYT-LPMO has experimentally found so far. The reported electron transfer between the active site copper and amino acids within LPMO resulting in tyrosyl- or tryptophanyl radicals indicates the presence of electron transfer pathways, which have been attributed to the protection of the active site during uncoupled turnover. ${ }^{47,48}$ The observed interaction is relatively weak, underlining the formation of a flexible and transient complex. This observation aligns well with the necessity of the LPMO to detach from the cellulose in order to receive an electron from $\mathrm{CDH}$, which fits very well to the proposed peroxide-dependent catalytic mechanism of LPMO. ${ }^{49}$ The apparent transient interaction also complements previous findings, ${ }^{45}$ hinting at a very dynamic system which depends on the interplay between electrostatic forces of its cofactors and thermodynamic forces governing domain movements.

The measured IPET rates all have the same order of magnitude, which indicates that the interaction mechanism did not evolve to recognize and favor specific CDH-LPMO combinations but is based on a universal recognition mechanism between the heme $b$ propionate $\mathrm{A}$ and the copper center, which depends little on surface complementarity. ${ }^{16}$ This is corroborated by reports on the interaction of different CDHs and LPMOs from N. crassa, ${ }^{6} \mathrm{CDH}$ and LPMO from different fungi ${ }^{1,2,50}$ and even from fungal $\mathrm{CDH}$ to bacterial LPMOs. ${ }^{51}$ The measured bimolecular rates for the final electron transfer step from CYT to LPMO were found to be very fast with values between $2.9 \times 10^{5}$ and $1.1 \times 10^{6} \mathrm{M}^{-1} \mathrm{~s}^{-1}$. A similar rate was also found for the very fast CYTcytochrome $c$ interaction $\left(10^{6} \mathrm{M}^{-1} \mathrm{~s}^{-1}\right){ }^{21}$ We conclude that the rate-determining driving force for IPET is not the redox potential difference between LPMO and CYT because CDHs with a $C_{B} T_{B}$ have a lower redox potential difference to LPMO but exhibit, in most cases, slightly faster IPET rates than $\mathrm{CYT}_{\mathrm{A}}$ featuring CDHs. Likewise, the IPET rates do not show a preferred complementarity of either the $\mathrm{CYT}_{\mathrm{A}}$ or $\mathrm{CYT}_{\mathrm{B}}$ surface with NcLPMO9C. This supports the previously published modeling of the CYT-LPMO interface, which shows that only a very small surface area of the domains besides the cofactors is involved in the recognition and interaction. ${ }^{16}$ Hence, the most important factor for the higher IPET rates of chimeric CDHs over the wild-type $\mathrm{CDHs}$ seems to stem from their preference of the open-state conformation induced by an unfitting CYT$\mathrm{DH}$ interface or linker.

\section{EXPERIMENTAL PROCEDURES}

Molecular Biology, Expression, and Purification. Genetic constructs of cdhIIA (NCU00206) and cdhIIB 
(NCU05923) were described previously ${ }^{7}$ and used for this study. A silent mutation (C456T) was introduced to the gene NCU05923 to delete the BstBI (Bsp119I) restriction site. Alignments using MEGA $6^{52}$ applying the BLOSSOM 62 algorithm together with the $3 \mathrm{D}$ structure analysis of NCU00206 (PDB ID: 4QI7) were applied to define exact borders of the individual domains (Table S4). Fragments of the individual domains were generated and joined to create four chimeric constructs by overlap extension PCR. The genetic integrity of the amplicons encoding chimeric CDHs was checked by DNA sequencing at Microsynth (Wolfurt, Austria). Following established methods, ${ }^{53}$ the constructs were expressed in a P. pastoris expression system $(\mathrm{KM} 71 \mathrm{H}$, Invitrogen). Best producing variants were preselected, ${ }^{54}$ cultivated in $500 \mathrm{~mL}$ scale fermentations (Figure S1), and purified by hydrophobic interaction (PHE-Sepharose Fast Flow, GE Healthcare) and anion exchange chromatography (Source $15 \mathrm{Q}, \mathrm{GE}$ Healthcare). Two chimeric $\mathrm{CDHs}\left(\mathrm{CDH}_{\mathrm{AAB}}\right.$ and $\left.\mathrm{CDH}_{\mathrm{BBA}}\right)$ still contained minor impurities after these two steps and were subjected to additional size exclusion chromatography (Superdex 75). The SDS-PAGE analysis of all preparations used in this study is displayed in Figure 1.

Enzyme Activity Assays and Protein Quantitation. The activity of CDHs was determined in $1 \mathrm{~mL}$ assays by following the reduction of either $0.3 \mathrm{mM} \mathrm{2,6-dichloroindo-}$ phenol (DCIP, $\varepsilon_{520}=6.8 \mathrm{mM}^{-1} \mathrm{~cm}^{-1}$ ) or $50 \mu \mathrm{M}$ cytochrome $c$ from equine heart $\left(\varepsilon_{550}=19.6 \mathrm{mM}^{-1} \mathrm{~cm}^{-1}\right)$. Assays were buffered with $100 \mathrm{mM}$ sodium citrate-phosphate buffer according to ref 55 at the indicated $\mathrm{pH}$. The $\mathrm{pH}$-dependent activity was measured with $30 \mathrm{mM}$ lactose as saturating substrate. Assay reactions were monitored for $180 \mathrm{~s}$ at $30^{\circ} \mathrm{C}$ at the indicated wavelengths in a LAMBDA $35 \mathrm{UV}-$ vis spectrophotometer equipped with a temperature-controlled 8-cell changer (PerkinElmer). The protein concentration of wild-type and chimeric $\mathrm{CDH}$ s was determined via the absorbance at $280 \mathrm{~nm}$ and the theoretical molar absorption coefficient $\varepsilon_{280}$ calculated with the Expasy Prot-Param program $^{56}$ using the mature amino acid sequence.

Spectroelectrochemistry. Spectroelectrochemical experiments were performed using $500 \mu \mathrm{L}$ samples containing around $50 \mu \mathrm{M}$ wild-type or chimeric $\mathrm{CDH}, 100 \mathrm{mM} \mathrm{KCl}, 100$ $\mathrm{mM}$ potassium phosphate buffer $\mathrm{pH}$ 6.0, and a redox mediator mixture comprising anthraquinone-1,5-disulfonate, 2-hydroxy1,4-naphthoquinone, indigo carmine, indigo trisulfonate, duroquinone, methylene blue, phenazine methosulfate, 1,2naphthoquinone and $N, N, N^{\prime}, N^{\prime}$-tetramethyl-p-phenylenediamine (all $3 \mu \mathrm{M})$, and methyl viologen $(150 \mu \mathrm{M})$. All experiments were carried out under anaerobic conditions at 25 ${ }^{\circ} \mathrm{C}$ in a thin-layer $(d=0.05 \mathrm{~mm})$ spectroelectrochemical cell (BASi, West Lafayette, IN; USA) with a standard threeelectrode setup comprising a $\mathrm{Ag} \mid \mathrm{AgCl}$-reference electrode (BASi), a platinum gauze (Goodfellow Cambridge Ltd., Huntington, England, UK) as the working electrode, and a platinum wire (Goodfellow Cambridge Ltd.) as the auxiliary electrode. Potentials were applied using a Gamry Series G 300 Potentiostat/Galvanostat/ZRA (Gamry Instruments, Warminster, PA, USA). A Whitley DG 250 Anaerobic Workstation (Don Whitley Scientific Ltd., Shipley, England, UK) was used to work under oxygen-free conditions. The reference electrode was calibrated against a saturated calomel electrode. All potentials are reported relative to the SHE. Nernst plots consisted of at least 5 data points, showed linear behavior, and were consistent with a one-electron redox process in the case of the heme $b$ and a two-electron process in the case of the FAD.

Voltammetry. Preparation of enzyme-modified electrodes started with the cleaning of gold disk-electrodes $(d=1.6 \mathrm{~mm}$, BASi, West Lafayette, IN, USA) by dipping in acidic piranha solution $\left[\mathrm{H}_{2} \mathrm{SO}_{4} / \mathrm{H}_{2} \mathrm{O}_{2}=3: 1(\mathrm{v} / \mathrm{v})\right]$ for $5 \mathrm{~min}$, cycling in 0.1 $\mathrm{M} \mathrm{NaOH}(-0.205$ to $-1.205 \mathrm{~V}$ vs $\mathrm{Ag} \mid \mathrm{AgCl}, 10$ cycles, $100 \mathrm{mV}$ $\mathrm{s}^{-1}$ ), polishing to mirror finish with aqueous alumina particles $(0.05 \mu \mathrm{m})$ on a MicroCloth (Buehler, Lake Bluff, IL, USA), ultrasonication to remove residual polishing particles and cycling in $0.5 \mathrm{M} \mathrm{H}_{2} \mathrm{SO}_{4}(-0.205$ to $+1.705 \mathrm{~V}$ vs $\mathrm{Ag} \mid \mathrm{AgCl}, 20$ cycles, $\left.200 \mathrm{mV} \mathrm{s}^{-1}\right)$. After rinsing with ultrapure water and drying with nitrogen gas the electrodes were immersed overnight in $10 \mathrm{mM}$ 1-thioglycerol dissolved in absolute ethanol for SAM formation. The electrodes were then washed with $20 \%$ ethanol to remove unbound thioglycerol, ultrapure water and dried over a stream of nitrogen gas. A custom-made Teflon holder was put over the electrode surface, leaving a cylindrical cavity with a volume of $\sim 20 \mu \mathrm{L}$ above the thioglycerol-modified gold surface. Then, a $100 \mu \mathrm{M} \mathrm{CDH}$ solution in $100 \mathrm{mM}$ Mcllvaine buffer, $\mathrm{pH}$ 6.0, was applied to the cavity. The assembly was covered with a dialysis membrane (45 $\mathrm{kDa}$ cut-off) held in place via a rubber O-ring.

Electrochemical experiments were carried out using a PGSTAT204 potentiostat/galvanostat (Metrohm Inula $\mathrm{GmbH}$, Vienna, Austria) with a standard three-electrode setup comprising the enzyme-modified gold electrode as working electrode, a platinum wire as the counter electrode, and a $\mathrm{Ag} \mid \mathrm{AgCl}$ electrode as the reference electrode. The 100 $\mathrm{mM}$ Mcllvaine buffer, $\mathrm{pH} 6.0$ contained $0.1 \mathrm{M} \mathrm{KCl}$ as the supporting electrolyte. A typical set of experiments comprised cyclic voltammetry of the thioglycerol-modified electrode (blank), the enzyme-modified thioglycerol-electrode, the enzyme-modified thioglycerol-electrode in the presence of 20 $\mathrm{mM}$ cellobiose, and the enzyme-modified thioglycerolelectrode in the presence of $20 \mathrm{mM}$ cellobiose and $50 \mu \mathrm{M}$ ferrocenemethanol. The applied potential window ranged from 5 to $550 \mathrm{mV}$ versus SHE. Scan rates were varied from 3 to 500 $\mathrm{mV} \mathrm{s}^{-1}$. Before the start of the experiment, the electrochemical cell containing buffer and the electrode setup was deoxygenated by purging with argon gas for $15 \mathrm{~min}$. The bulk solution was not agitated during the measurement which was performed at $25^{\circ} \mathrm{C}$.

Cyclic voltammograms were analyzed using NOVA software (Metrohm) and Microsoft Excel. To evaluate whether freely diffusing or adsorbed $\mathrm{CDH}$ species dominate the electrochemical process, the linearity of plots of peak current versus the square root of the scan rate was analyzed. Reversibility, quasi-reversibility, or irreversibility of the electron transfer process was assessed by the shape of the voltammograms and the peak-to-peak separation. Standard heterogeneous electron transfer rate constants $k^{0}$ were calculated using the model for quasi-reversible processes described by Nicholson \& Shain ${ }^{57}$ and Matsuda \& Ayabe ${ }^{58}$ with a transfer coefficient of $\alpha=0.5$ and interpolated values $\left[\Psi=1 /(-2.46+0.041) * \mathrm{~d} E_{\mathrm{p}}\right]$ of the kinetic parameter $\Psi$ for the scan rate-dependent peak potential separation. Diffusion coefficients for $\mathrm{CDH}$ were calculated from the slope of the linear correlation of the anodic or cathodic peak currents, the square root of the scan rate, the active electrode surface area $\left(A=0.0177 \mathrm{~cm}^{2}\right)$, and an enzyme concentration of $100 \mu \mathrm{M}\left(10^{-7} \mathrm{~mol} \mathrm{~cm}^{-3}\right)$ applying the Randles-Sevcik equation. ${ }^{59,60}$ Peak currents were assessed by 
applying Nicholson's empiric equation $I_{\mathrm{pa}} / I_{\mathrm{pc}}=\left(I_{\mathrm{pa}}\right)_{0} / I_{\mathrm{pc}}+$ $0.485\left(I_{\mathrm{sp}}\right)_{0} / \mathrm{Ipc}+0.086$. $^{39}$

Presteady-State Kinetic Studies. The rapid spectral changes induced by substrate oxidation and the resulting change of the redox state of the $\mathrm{CDH}$ cofactors were followed with a SX-20 stopped-flow instrument (Applied Photophysics, Leatherhead, UK) equipped with a photomultiplier tube (AP/ PMT.R928). The redox state of the FAD cofactor was monitored at the appropriate isosbestic point $(449 \mathrm{~nm})$ of the heme $b$ cofactor, which itself was monitored at $563 \mathrm{~nm}$. The observed rates $\left(k_{\mathrm{obs}}\right)$ for the indicated cellobiose concentrations were estimated by fitting the data to a single exponential function. The reduction of NcLPMO9C by CDH was studied using a UV-vis photodiode array detector (AP/ SXPDAUV) in the sequential mixing mode. $\mathrm{CDH}$ was fully reduced in the first step by mixing with an appropriate concentration of cellobiose in air-saturated buffer. The reaction was held in an ageing loop until full reoxidation of the FAD cofactor occurred via its weak oxidase activity. Approx. $70 \%$ of the heme $b$ remained reduced because of its slower interaction with $\mathrm{O}_{2}$. The partially reoxidized $\mathrm{CDH}$ was rapidly mixed with NcLPMO9C. The observed rates of transfer were estimated by following the redox state of the CYT domain of $\mathrm{CDH}$ and fitting the data of $A_{563}$ to a single exponential curve. All presteady-state experiments were performed in $100 \mathrm{mM}$ sodium citrate-phosphate buffer, $\mathrm{pH} 6.0$ at $30{ }^{\circ} \mathrm{C}$.

Modeling of CDH Chimeras. SWISS-MODEL ${ }^{61-63}$ was used to generate structure-guided homology models of the CYT and dehydrogenase (DH) domains of NcCDHIIB (ORF: NCU05923) using the crystal structure of NcCDHIIA (PDB ID: 4 QI7 $)^{9}$ as a template. Steepest descent energy minimization with 2500 steps (initial step size of $0.1 \mathrm{~nm}$ ) was performed with the GROMOS software package for molecular simulation ${ }^{64}$ using the $54 a 7$ force field ${ }^{65,66}$ as a further refinement for the resulting homology models. Subsequently, the complexes $\mathrm{CYT}_{\mathrm{A}}-\mathrm{DH}_{\mathrm{A}}, \mathrm{CYT}_{\mathrm{A}}-\mathrm{DH}_{\mathrm{B}}$, $\mathrm{CYT}_{\mathrm{B}}-\mathrm{DH}_{\mathrm{A}}$, and $\mathrm{CYT}_{\mathrm{B}}-\mathrm{DH}_{\mathrm{B}}$ have been modeled using HADDOCK $2.2^{25,26}$ with interaction restraints between heme $b$ and the Arg697 and Arg719 for NcCDHIIA and NcCDHIIB, respectively. The number of starting structures was set to 1000 and refined to 200 structures. Nonbonded energy values (i.e., van der Waals and electrostatic energies) were taken from the HADDOCK output and the angles of the CYT domain relative to the DH domain around three axes defined by two (virtual) atoms $\mathrm{j}$ and $\mathrm{k}$ was measured by computing the dihedral angle $i-j-k-l$ with the (virtual) atoms, as listed in Table S2. The distance-field reaction coordinate ${ }^{28}$ was used to estimate the shortest distance between the linker anchor points along a path that does not pass through the protein domains. Electrostatic surface representations, as well as protonation states, were computed with PROPKA 3.1, ${ }^{67,68} \mathrm{PDB} \mathrm{PQR}^{69}$ and the PyMOL APBS plug-in. ${ }^{70-74}$ Binding affinities were predicted with PRODIGY.

H/D Exchange Mass Spectrometry. Prior to the mass spectrometric analyses, NcCDHIIA was deglycosylated under nondenaturing conditions as utilized previously for the analyses of $\mathrm{CDH}$ from $M$. thermophilum. ${ }^{35} \mathrm{CDH}$ was incubated overnight with $15 \mathrm{U}$ Endo Hf (New England Biolabs, USA) per $1 \mu \mathrm{g}$ of protein at $37^{\circ} \mathrm{C}$ in $50 \mathrm{mM}$ sodium acetate buffer $\mathrm{pH} 5.75$ to detach the $\mathrm{N}$-glycans. The deglycosylated $\mathrm{CDH}$ was preincubated alone or in a mixture with NcLPMO9F (1:3 and 3:1 $\mathrm{M}$ ratios) in $\mathrm{H}_{2} \mathrm{O}$-based $50 \mathrm{mM}$ sodium acetate buffer $\mathrm{pH} 5.75$ for $30 \mathrm{~min}$. After preincubation, the deuterium labeling was started by a 10 -fold dilution of the protein samples into a deuterated buffer ( $50 \mathrm{mM}$ sodium acetate $\mathrm{pD} 5.75)$. The final protein concentration during the labeling was $5 \mu \mathrm{M}$ for the examined protein and $15 \mu \mathrm{M}$ for the interaction partner. The deuteration reaction proceeded at $21{ }^{\circ} \mathrm{C}$ and $50 \mu \mathrm{L}$ aliquots were removed after $0.33,1,3,10,30,60,180$, and 300 min. The rest of the HDX-MS workflow, including the stopping of the exchange in the aliquots, denaturation of samples, and their online enzymatic digestion by immobilized porcine pepsin, LC-MS analysis by Fourier transform ion cyclotron resonance mass spectrometry and data processing, was performed exactly as optimized for M. thermophilum $\mathrm{CDH}$ as described elsewhere. ${ }^{35}$

Statistical Analysis. A statistical evaluation of the data set, which aimed to identify significant correlations of individual variables using bivariate correlation analysis and PCA has been performed using the software R Studio (MA, USA) and the packages FactoMiner ${ }^{78}$ and Psych. ${ }^{79}$ Selected code snippets describing the libraries used, the intermediate data produced, as well as the code generating tables and plots are presented in the statistical analysis section (SA) in the Supporting Information. The full $\mathrm{R}$ script and data set has been released in a public repository (https://doi.org/10.5281/zenodo. 4297843).

\section{ASSOCIATED CONTENT}

\section{Supporting Information}

The Supporting Information is available free of charge at https://pubs.acs.org/doi/10.1021/acscatal.0c05294.

Protein production, electrochemical characterization, modeling, and statistical analysis (PDF)

\section{AUTHOR INFORMATION}

\section{Corresponding Author}

Roland Ludwig - Biocatalysis and Biosensing Research Group, Department of Food Science and Technology, BOKU-University of Natural Resources and Life Sciences, 1190 Vienna, Austria; (i) orcid.org/0000-0002-5058-5874; Phone: +431 47654 75216; Email: roland.ludwig@ boku.ac.at

\section{Authors}

Alfons K. G. Felice - Biocatalysis and Biosensing Research Group, Department of Food Science and Technology, BOKU-University of Natural Resources and Life Sciences, 1190 Vienna, Austria

Christian Schuster - Biocatalysis and Biosensing Research Group, Department of Food Science and Technology, BOKU-University of Natural Resources and Life Sciences, 1190 Vienna, Austria

Alan Kadek - BIOCEV-Institute of Microbiology, The Czech Academy of Sciences, 25250 Vestec, Czech Republic; Department of Biochemistry, Faculty of Science, Charles University in Prague, 12843 Prague, Czech Republic

Frantisek Filandr - BIOCEV-Institute of Microbiology, The Czech Academy of Sciences, 25250 Vestec, Czech Republic; Department of Biochemistry, Faculty of Science, Charles University in Prague, 12843 Prague, Czech Republic

Christophe V. F. P. Laurent - Biocatalysis and Biosensing Research Group, Department of Food Science and Technology and Department of Material Sciences and Process Engineering, BOKU-University of Natural Resources and 
Life Sciences, 1190 Vienna, Austria; 이잉.org/00000002-9112-6981

Stefan Scheiblbrandner - Biocatalysis and Biosensing Research Group, Department of Food Science and Technology, BOKU-University of Natural Resources and Life Sciences, 1190 Vienna, Austria

Lorenz Schwaiger - Biocatalysis and Biosensing Research Group, Department of Food Science and Technology, BOKU-University of Natural Resources and Life Sciences, 1190 Vienna, Austria

Franziska Schachinger - Biocatalysis and Biosensing Research Group, Department of Food Science and Technology, BOKU-University of Natural Resources and Life Sciences, 1190 Vienna, Austria

Daniel Kracher - Biocatalysis and Biosensing Research Group, Department of Food Science and Technology, BOKU-University of Natural Resources and Life Sciences, 1190 Vienna, Austria

Christoph Sygmund - Biocatalysis and Biosensing Research Group, Department of Food Science and Technology, BOKU-University of Natural Resources and Life Sciences, 1190 Vienna, Austria

Petr Man - BIOCEV-Institute of Microbiology, The Czech Academy of Sciences, 25250 Vestec, Czech Republic; Department of Biochemistry, Faculty of Science, Charles University in Prague, 12843 Prague, Czech Republic

Petr Halada - BIOCEV-Institute of Microbiology, The Czech Academy of Sciences, 25250 Vestec, Czech Republic

Chris Oostenbrink - Department of Material Sciences and Process Engineering, BOKU-University of Natural Resources

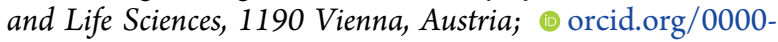
0002-4232-2556

Complete contact information is available at:

https://pubs.acs.org/10.1021/acscatal.0c05294

\section{Author Contributions}

A.K.G.F. wrote the first draft of the manuscript and performed together with Christian Schuster and Christoph Sygmund the production and purification of chimeric $\mathrm{CDHs}$ and steady-state kinetic measurements. C.V.F.P.L. and C.O. performed and interpreted docking and modeling studies. A.K., F.F., P.M., and P.H. performed and analyzed $\mathrm{H} / \mathrm{D}$ exchange experiments, A.K.G.F. and D.K. performed and analyzed fast-kinetic experiments, S.S., A.K.G.F, L.S., and F.S. performed and analyzed electrochemical experiments. R.L. initiated the study, designed experiments, evaluated and interpreted data, and wrote the final draft of the manuscript together with C.O, P.M., and P.H.

\section{Funding}

This work was funded by the Austrian Science Fund (project I2385-N28) and the Czech Science Foundation (projects 1634818L) and the Europeans Union's Horizon 2020 research and innovation programme (ERC Consolidator Grant OXIDISE) under grant agreement no. 726396. A.K.G.F. was supported by a scholarship of the Austrian Academy of Sciences (DOC scholarship), S.S. by the MBW FM (Austrian Federal Ministry of Science, Research and Economy) International Graduate School BioNano Technology (IGS BioNano Tech) and C.V.F.P.L., L.S., F.S., and D.K. by the doctoral programme BioToP (W1224) funded by the Austrian Science Fund. A.K.G.F. was supported by a Doc fellowship of the Austrian Academy of Science. Access to the MS facility was enabled by MEYS CR (CZ.1.05/1.1.00/02.0109, LQ1604 and LM2015043 CIISB) funding.

\section{Notes}

The authors declare no competing financial interest.

\section{ACKNOWLEDGMENTS}

Daniela Gamperl is acknowledged for her fantastic work to produce chimeric $\mathrm{CDH}_{\mathrm{ABA}}$.

\section{ABBREVIATIONS}

$\mathrm{AFM}$, atomic force microscopy; $\mathrm{CDH}$, cellobiose dehydrogenase; CYT, cytochrome domain; DCIP, 2,6-dichloroindophenol; $\mathrm{DH}$, dehydrogenase domain; $\mathrm{FAD}$, flavin adenine dinucleotide; HDX, hydrogen/deuterium exchange; IDET, interdomain electron transfer; IPET, interprotein electron transfer; LPMO, lytic polysaccharide monooxygenase; MS, mass spectrometry; SAM, self-assembled monolayer; SANS, small-angle neutron scattering; SAXS, small-angle X-ray scattering; SHE, standard hydrogen electrode; TN, turnover number

\section{REFERENCES}

(1) Langston, J. A.; Shaghasi, T.; Abbate, E.; Xu, F.; Vlasenko, E.; Sweeney, M. D. Oxidoreductive Cellulose Depolymerization by the Enzymes Cellobiose Dehydrogenase and Glycoside Hydrolase 61. Appl. Environ. Microbiol. 2011, 77, 7007-7015.

(2) Phillips, C. M.; Beeson, W. T.; Cate, J. H.; Marletta, M. A. Cellobiose Dehydrogenase and a Copper-Dependent Polysaccharide Monooxygenase Potentiate Cellulose Degradation by Neurospora crassa. ACS Chem. Biol. 2011, 6, 1399-1406.

(3) Phillips, C. M.; Iavarone, A. T.; Marletta, M. A. Quantitative Proteomic Approach for Cellulose Degradation by Neurospora crassa. J. Proteome Res. 2011, 10, 4177-4185.

(4) Harris, P. V.; Welner, D.; McFarland, K. C.; Re, E.; Navarro Poulsen, J.-C.; Brown, K.; Salbo, R.; Ding, H.; Vlasenko, E.; Merino, S.; Xu, F.; Cherry, J.; Larsen, S.; Lo Leggio, L. Stimulation of Lignocellulosic Biomass Hydrolysis by Proteins of Glycoside Hydrolase Family 61: Structure and Function of a Large, Enigmatic Family. Biochemistry 2010, 49, 3305-3316.

(5) Quinlan, R. J.; Sweeney, M. D.; Lo Leggio, L.; Otten, H.; Poulsen, J.-C. N.; Johansen, K. S.; Krogh, K. B. R. M.; Jorgensen, C. I.; Tovborg, M.; Anthonsen, A.; Tryfona, T.; Walter, C. P.; Dupree, P.; Xu, F.; Davies, G. J.; Walton, P. H. Insights into the Oxidative Degradation of Cellulose by a Copper Metalloenzyme That Exploits Biomass Components. Proc. Natl. Acad. Sci. U.S.A. 2011, 108, 1507915084.

(6) Kracher, D.; Scheiblbrandner, S.; Felice, A. K. G.; Breslmayr, E.; Preims, M.; Ludwicka, K.; Haltrich, D.; Eijsink, V. G. H.; Ludwig, R. Extracellular Electron Transfer Systems Fuel Cellulose Oxidative Degradation. Science 2016, 352, 1098-1101.

(7) Sygmund, C.; Kracher, D.; Scheiblbrandner, S.; Zahma, K.; Felice, A. K. G.; Harreither, W.; Kittl, R.; Ludwig, R. Characterization of the Two Neurospora crassa Cellobiose Dehydrogenases and Their Connection to Oxidative Cellulose Degradation. Appl. Environ. Microbiol. 2012, 78, 6161-6171.

(8) Igarashi, K.; Yoshida, M.; Matsumura, H.; Nakamura, N.; Ohno, H.; Samejima, M.; Nishino, T. Electron Transfer Chain Reaction of the Extracellular Flavocytochrome Cellobiose Dehydrogenase from the Basidiomycete Phanerochaete chrysosporium. FEBS J. 2005, 272, 2869-2877.

(9) Tan, T.-C.; Kracher, D.; Gandini, R.; Sygmund, C.; Kittl, R.; Haltrich, D.; Hällberg, B. M.; Ludwig, R.; Divne, C. Structural Basis for Cellobiose Dehydrogenase Action during Oxidative Cellulose Degradation. Nat. Commun. 2015, 6, 7542.

(10) Igarashi, K.; Momohara, I.; Nishino, T.; Samejima, M. Kinetics of Inter-Domain Electron Transfer in Flavocytochrome Cellobiose 
Dehydrogenase from the White-Rot Fungus Phanerochaete chrysosporium. Biochem. J. 2002, 365, 521.

(11) Kracher, D.; Zahma, K.; Schulz, C.; Sygmund, C.; Gorton, L.; Ludwig, R. Inter-Domain Electron Transfer in Cellobiose Dehydrogenase: Modulation by $\mathrm{pH}$ and Divalent Cations. FEBS J. 2015, 282, 3136-3148.

(12) Bodenheimer, A. M.; O’Dell, W. B.; Oliver, R. C.; Qian, S.; Stanley, C. B.; Meilleur, F. Structural Investigation of Cellobiose Dehydrogenase IIA: Insights from Small Angle Scattering into Intraand Intermolecular Electron Transfer Mechanisms. Biochim. Biophys. Acta, Gen. Subj. 2018, 1862, 1031-1039.

(13) Bodenheimer, A. M.; O'Dell, W. B.; Stanley, C. B.; Meilleur, F. Structural Studies of Neurospora crassa LPMO9D and Redox Partner CDHIIA Using Neutron Crystallography and Small-Angle Scattering. Carbohydr. Res. 2017, 448, 200-204.

(14) Harada, H.; Onoda, A.; Uchihashi, T.; Watanabe, H.; Sunagawa, N.; Samejima, M.; Igarashi, K.; Hayashi, T. Interdomain Flip-Flop Motion Visualized in Flavocytochrome Cellobiose Dehydrogenase Using High-Speed Atomic Force Microscopy during Catalysis. Chem. Sci. 2017, 8, 6561-6565.

(15) Courtade, G.; Wimmer, R.; Røhr, Å. K.; Preims, M.; Felice, A. K. G.; Dimarogona, M.; Vaaje-Kolstad, G.; Sørlie, M.; Sandgren, M.; Ludwig, R.; Eijsink, V. G. H.; Aachmann, F. L. Interactions of a Fungal Lytic Polysaccharide Monooxygenase with $\beta$-Glucan Substrates and Cellobiose Dehydrogenase. Proc. Natl. Acad. Sci. U.S.A. 2016, 113, 5922-5927.

(16) Laurent, C. V. F. P.; Breslmayr, E.; Tunega, D.; Ludwig, R.; Oostenbrink, C. Interaction between Cellobiose Dehydrogenase and Lytic Polysaccharide Monooxygenase. Biochemistry 2019, 58, 12261235.

(17) Ortiz, R.; Matsumura, H.; Tasca, F.; Zahma, K.; Samejima, M.; Igarashi, K.; Ludwig, R.; Gorton, L. Effect of Deglycosylation of Cellobiose Dehydrogenases on the Enhancement of Direct Electron Transfer with Electrodes. Anal. Chem. 2012, 84, 10315-10323.

(18) Hallberg, B. M.; Henriksson, G.; Pettersson, G.; Divne, C. Crystal Structure of the Flavoprotein Domain of the Extracellular Flavocytochrome Cellobiose Dehydrogenase. J. Mol. Biol. 2002, 315, 421-434.

(19) Zamocky, M.; Ludwig, R.; Peterbauer, C.; Hallberg, B.; Divne, C.; Nicholls, P.; Haltrich, D. Cellobiose Dehydrogenase-a Flavocytochrome from Wood-Degrading, Phytopathogenic and Saprotropic Fungi. Curr. Protein Pept. Sci. 2006, 7, 255-280.

(20) Mason, M. G.; Wilson, M. T.; Ball, A.; Nicholls, P. Oxygen Reduction by Cellobiose Oxidoreductase: The Role of the Haem Group. FEBS Lett. 2002, 518, 29-32.

(21) Mason, M. G.; Nicholls, P.; Divne, C.; Hallberg, B. M.; Henriksson, G.; Wilson, M. T. The Heme Domain of Cellobiose Oxidoreductase: A One-Electron Reducing System. Biochim. Biophys. Acta, Rev. Bioenerg. 2003, 1604, 47-54.

(22) Samejima, M.; Phillips, R. S.; Eriksson, K.-E. L. Cellobiose Oxidase from Phanerochaete chrysosporium Stopped-Flow Spectrophotometric Analysis of pH-Dependent Reduction. FEBS Lett. 1992, 306, $165-168$.

(23) Moser, C. C.; Keske, J. M.; Warncke, K.; Farid, R. S.; Dutton, P. L. Nature of Biological Electron Transfer. Nature 1992, 355, 796802.

(24) Page, C. C.; Moser, C. C.; Chen, X.; Dutton, P. L. Natural Engineering Principles of Electron Tunnelling in Biological Oxidation-Reduction. Nature 1999, 402, 47-52.

(25) Dominguez, C.; Boelens, R.; Bonvin, A. M. J. J. HADDOCK: A Protein-Protein Docking Approach Based on Biochemical or Biophysical Information. J. Am. Chem. Soc. 2003, 125, 1731-1737.

(26) de Vries, S. J.; van Dijk, A. D. J.; Krzeminski, M.; van Dijk, M.; Thureau, A.; Hsu, V.; Wassenaar, T.; Bonvin, A. M. J. J. HADDOCK versus HADDOCK: New Features and Performance of HADDOCK2.0 on the CAPRI Targets. Proteins: Struct., Funct., Bioinf. 2007, 69, 726-733.

(27) Eichenberger, A. P.; Allison, J. R.; Dolenc, J.; Geerke, D. P.; Horta, B. A. C.; Meier, K.; Oostenbrink, C.; Schmid, N.; Steiner, D.;
Wang, D.; van Gunsteren, W. F. GROMOS++ Software for the Analysis of Biomolecular Simulation Trajectories. J. Chem. Theory Comput. 2011, 7, 3379-3390.

(28) de Ruiter, A.; Oostenbrink, C. Protein-Ligand Binding from Distancefield Distances and Hamiltonian Replica Exchange Simulations. J. Chem. Theory Comput. 2013, 9, 883-892.

(29) Xue, L. C.; Rodrigues, J. P.; Kastritis, P. L.; Bonvin, A. M.; Vangone, A. PRODIGY: A Web Server for Predicting the Binding Affinity of Protein-Protein Complexes. Bioinformatics 2016, 32, $3676-3678$

(30) Kastritis, P. L.; Rodrigues, J. P. G. L. M.; Folkers, G. E.; Boelens, R.; Bonvin, A. M. J. J. Proteins Feel More Than They See: Fine-Tuning of Binding Affinity by Properties of the Non-Interacting Surface. J. Mol. Biol. 2014, 426, 2632-2652.

(31) Vangone, A.; Bonvin, A. M. Contacts-Based Prediction of Binding Affinity in Protein-Protein Complexes. eLife 2015, 4, No. e07454.

(32) Janin, J.; Bahadur, R. P.; Chakrabarti, P. Protein-Protein Interaction and Quaternary Structure. Q. Rev. Biophys. 2008, 41, 133180.

(33) Li, X.; Beeson, W. T.; Phillips, C. M.; Marletta, M. A.; Cate, J. H. D. Structural Basis for Substrate Targeting and Catalysis by Fungal Polysaccharide Monooxygenases. Structure 2012, 20, 1051-1061.

(34) Kittl, R.; Kracher, D.; Burgstaller, D.; Haltrich, D.; Ludwig, R. Production of Four Neurospora crassa Lytic Polysaccharide Monooxygenases in Pichia Pastoris Monitored by a Fluorimetric Assay. Biotechnol. Biofuels 2012, 5, 79.

(35) Kadek, A.; Kavan, D.; Felice, A. K. G.; Ludwig, R.; Halada, P.; Man, P. Structural Insight into the Calcium Ion Modulated Interdomain Electron Transfer in Cellobiose Dehydrogenase. FEBS Lett. 2015, 589, 1194-1199.

(36) Konermann, L.; Vahidi, S.; Sowole, M. A. Mass Spectrometry Methods for Studying Structure and Dynamics of Biological Macromolecules. Anal. Chem. 2014, 86, 213-232.

(37) Sowole, M. A.; Konermann, L. Effects of Protein-Ligand Interactions on Hydrogen/Deuterium Exchange Kinetics: Canonical and Noncanonical Scenarios. Anal. Chem. 2014, 86, 6715-6722.

(38) Lindgren, A.; Larsson, T.; Ruzgas, T.; Gorton, L. Direct Electron Transfer between the Heme of Cellobiose Dehydrogenase and Thiol Modified Gold Electrodes. J. Electroanal. Chem. 2000, 494, 105-113.

(39) Nicholson, R. S. Theory and Application of Cyclic Voltammetry for Measurement of Electrode Reaction Kinetics. Anal. Chem. 1965, 37, 1351-1355.

(40) Bowden, E. F.; Hawkridge, F. M.; Blount, H. N. Interfacial Electrochemistry of Cytochrome $\mathrm{c}$ at Tin Oxide, Indium Oxide, Gold, and Platinum Electrodes. J. Electroanal. Chem. Interfacial Electrochem. 1984, 161, 355-376.

(41) Raices, M.; Paifer, E.; Cremata, J.; Montesino, R.; Ståhlberg, J.; Divne, C.; Szabó, I. J.; Henriksson, G.; Johansson, G.; Pettersson, G. Cloning and Characterization of a CDNA Encoding a Cellobiose Dehydrogenase from the White Rot Fungus Phanerochaete chrysosporium. FEBS Lett. 1995, 369, 233-238.

(42) Hallberg, B. M.; Bergfors, T.; Bäckbro, K.; Pettersson, G.; Henriksson, G.; Divne, C. A New Scaffold for Binding Haem in the Cytochrome Domain of the Extracellular Flavocytochrome Cellobiose Dehydrogenase. Structure 2000, 8, 79-88.

(43) Diêp Lê, K. H.; Lederer, F.; Golinelli-Pimpaneau, B. Structural Evidence for the Functional Importance of the Heme Domain Mobility in Flavocytochrome b2. J. Mol. Biol. 2010, 400, 518-530.

(44) Vaaje-Kolstad, G.; Westereng, B.; Horn, S. J.; Liu, Z.; Zhai, H.; Sørlie, M.; Eijsink, V. G. H. An Oxidative Enzyme Boosting the Enzymatic Conversion of Recalcitrant Polysaccharides. Science 2010, 330, 219-222.

(45) Kadek, A.; Kavan, D.; Marcoux, J.; Stojko, J.; Felice, A. K. G.; Cianférani, S.; Ludwig, R.; Halada, P.; Man, P. Interdomain Electron Transfer in Cellobiose Dehydrogenase Is Governed by Surface Electrostatics. Biochim. Biophys. Acta, Gen. Subj. 2017, 1861, 157-167. 
(46) Harreither, W.; Sygmund, C.; Augustin, M.; Narciso, M.; Rabinovich, M. L.; Gorton, L.; Haltrich, D.; Ludwig, R. Catalytic Properties and Classification of Cellobiose Dehydrogenases from Ascomycetes. Appl. Environ. Microbiol. 2011, 77, 1804-1815.

(47) Jones, S. M.; Transue, W. J.; Meier, K. K.; Kelemen, B.; Solomon, E. I. Kinetic Analysis of Amino Acid Radicals Formed in $\mathrm{H}_{2} \mathrm{O}_{2}$-Driven CuI LPMO Reoxidation Implicates Dominant Homolytic Reactivity. Proc. Natl. Acad. Sci. U.S.A. 2020, 117, 11916-11922.

(48) Paradisi, A.; Johnston, E. M.; Tovborg, M.; Nicoll, C. R.; Ciano, L.; Dowle, A.; McMaster, J.; Hancock, Y.; Davies, G. J.; Walton, P. H. Formation of a Copper(II)-Tyrosyl Complex at the Active Site of Lytic Polysaccharide Monooxygenases Following Oxidation by $\mathrm{H}_{2} \mathrm{O}_{2}$. J. Am. Chem. Soc. 2019, 141, 18585-18599.

(49) Chylenski, P.; Bissaro, B.; Sørlie, M.; Røhr, Å. K.; Várnai, A.; Horn, S. J.; Eijsink, V. G. H. Lytic Polysaccharide Monooxygenases in Enzymatic Processing of Lignocellulosic Biomass. ACS Catal. 2019, 9, 4970-4991.

(50) Petrović, D. M.; Várnai, A.; Dimarogona, M.; Mathiesen, G.; Sandgren, M.; Westereng, B.; Eijsink, V. G. H. Comparison of Three Seemingly Similar Lytic Polysaccharide Monooxygenases from Neurospora crassa Suggests Different Roles in Plant Biomass Degradation. J. Biol. Chem. 2019, 294, 15068-15081.

(51) Loose, J. S. M.; Forsberg, Z.; Kracher, D.; Scheiblbrandner, S.; Ludwig, R.; Eijsink, V. G. H.; Vaaje-Kolstad, G. Activation of Bacterial Lytic Polysaccharide Monooxygenases with Cellobiose Dehydrogenase. Protein Sci. 2016, 25, 2175-2186.

(52) Tamura, K.; Stecher, G.; Peterson, D.; Filipski, A.; Kumar, S. MEGA6: Molecular Evolutionary Genetics Analysis Version 6.0. Mol. Biol. Evol. 2013, 30, 2725-2729.

(53) Harreither, W.; Felice, A. K. G.; Paukner, R.; Gorton, L.; Ludwig, R.; Sygmund, C. Recombinantly Produced Cellobiose Dehydrogenase from Corynascus thermophilus for Glucose Biosensors and Biofuel Cells. Biotechnol. J. 2012, 7, 1359-1366.

(54) Weis, R.; Luiten, R.; Skranc, W.; Schwab, H.; Wubbolts, M.; Glieder, A. Reliable High-Throughput Screening with Pichia Pastoris by Limiting Yeast Cell Death Phenomena. FEMS Yeast Res. 2004, 5, 179-189.

(55) Mcllvaine, T. C. A Buffer Solution for Colorimetric Comparison. J. Biol. Chem. 1921, 49, 183-186.

(56) Gasteiger, E.; Hoogland, C.; Gattiker, A.; Duvaud, S.; Wilkins, M. R.; Appel, R. D.; Bairoch, A. Protein Identification and Analysis Tools on the ExPASy Server. In The Proteomics Protocols Handbook; Walker, J. M., Ed.; Humana Press: Totowa, NJ, 2005; pp 571-607.

(57) Nicholson, R. S.; Shain, I. Theory of Stationary Electrode Polarography. Single Scan and Cyclic Methods Applied to Reversible, Irreversible, and Kinetic Systems. Anal. Chem. 1964, 36, 706-723.

(58) Matsuda, H. Zur Theorie der Wechselspannungs-Polarographie. Z. für Elektrochem. Berichte Bunsenges. für Phys. Chem. 1958, 62, 977-989.

(59) Sevčík, A. Oscillographic Polarography with Periodical Triangular Voltage. Collect. Czech. Chem. Commun. 1948, 13, 349377.

(60) Randles, J. E. B. A Cathode Ray Polarograph Part II.-The Current-Voltage Curves. Trans. Faraday Soc. 1948, 44, 327-338.

(61) Arnold, K.; Bordoli, L.; Kopp, J.; Schwede, T. The SWISSMODEL Workspace: A Web-Based Environment for Protein Structure Homology Modelling. Bioinformatics 2006, 22, 195-201.

(62) Benkert, P.; Biasini, M.; Schwede, T. Toward the Estimation of the Absolute Quality of Individual Protein Structure Models. Bioinformatics 2011, 27, 343-350.

(63) Biasini, M.; Bienert, S.; Waterhouse, A.; Arnold, K.; Studer, G.; Schmidt, T.; Kiefer, F.; Cassarino, T. G.; Bertoni, M.; Bordoli, L.; Schwede, T. SWISS-MODEL: Modelling Protein Tertiary and Quaternary Structure Using Evolutionary Information. Nucleic Acids Res. 2014, 42, W252-W258.

(64) Schmid, N.; Christ, C. D.; Christen, M.; Eichenberger, A. P.; van Gunsteren, W. F. Architecture, Implementation and Parallelisation of the GROMOS Software for Biomolecular Simulation. Comput. Phys. Commun. 2012, 183, 890-903.
(65) Schmid, N.; Eichenberger, A. P.; Choutko, A.; Riniker, S.; Winger, M.; Mark, A. E.; van Gunsteren, W. F. Definition and Testing of the GROMOS Force-Field Versions 54A7 and 54B7. Eur. Biophys. J. 2011, 40, 843-856.

(66) Poger, D.; Van Gunsteren, W. F.; Mark, A. E. A New Force Field for Simulating Phosphatidylcholine Bilayers. J. Comput. Chem. 2010, 31, 1117-1125.

(67) Olsson, M. H. M.; Søndergaard, C. R.; Rostkowski, M.; Jensen, J. H. PROPKA3: Consistent Treatment of Internal and Surface Residues in Empirical pKa Predictions. J. Chem. Theory Comput. 2011, $7,525-537$.

(68) Søndergaard, C. R.; Olsson, M. H. M.; Rostkowski, M.; Jensen, J. H. Improved Treatment of Ligands and Coupling Effects in Empirical Calculation and Rationalization of pKa Values. J. Chem. Theory Comput. 2011, 7, 2284-2295.

(69) Dolinsky, T. J.; Nielsen, J. E.; McCammon, J. A.; Baker, N. A. PDB2PQR: An Automated Pipeline for the Setup of PoissonBoltzmann Electrostatics Calculations. Nucleic Acids Res. 2004, 32, W665-W667.

(70) Baker, N. A.; Sept, D.; Joseph, S.; Holst, M. J.; McCammon, J. A. Electrostatics of Nanosystems: Application to Microtubules and the Ribosome. Proc. Natl. Acad. Sci. U.S.A. 2001, 98, 10037-10041.

(71) Bank, R. E.; Holst, M. A New Paradigm for Parallel Adaptive Meshing Algorithms. SIAM Rev. 2003, 45, 291-323.

(72) Holst, M. Adaptive Numerical Treatment of Elliptic Systems on Manifolds. Adv. Comput. Math. 2001, 15, 139-191.

(73) Holst, M.; Saied, F. Multigrid Solution of the PoissonBoltzmann Equation. J. Comput. Chem. 1993, 14, 105-113.

(74) Holst, M. J.; Saied, F. Numerical Solution of the Nonlinear Poisson-Boltzmann Equation: Developing More Robust and Efficient Methods. J. Comput. Chem. 1995, 16, 337-364.

(75) Kastritis, P. L.; Rodrigues, J. P. G. L. M.; Folkers, G. E.; Boelens, R.; Bonvin, A. M. J. J. Proteins Feel More Than They See: Fine-Tuning of Binding Affinity by Properties of the Non-Interacting Surface. J. Mol. Biol. 2014, 426, 2632-2652.

(76) Vangone, A.; Bonvin, A. M. Contacts-Based Prediction of Binding Affinity in Protein-Protein Complexes. eLife 2015, 4, No. e07454.

(77) Xue, L. C.; Rodrigues, J. P.; Kastritis, P. L.; Bonvin, A. M.; Vangone, A. PRODIGY: A Web Server for Predicting the Binding Affinity of Protein-Protein Complexes. Bioinformatics 2016, 32, $3676-3678$.

(78) Lê, S.; Josse, J.; Husson, F. FactoMineR: An R Package for Multivariate Analysis. J. Stat. Software 2008, 25, 1.

(79) Revelle, W. R. Psych: Procedures for Personality and Psychological Research, 2017. 